\title{
WERTORIENTIERUNG
}

GOVERNANCE
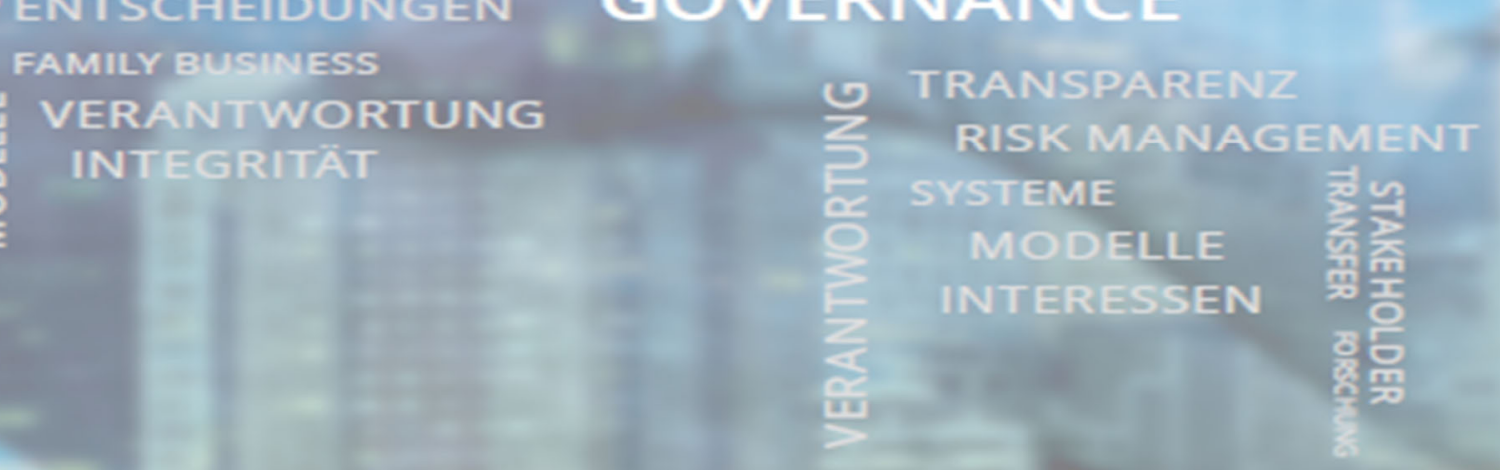

\section{Implementierungsstand des Compliance-Managements in der Unternehmenspraxis}

Studienserie „Erfolgsfaktoren der Unternehmensführung “"

Band 4, ISBN 978-3-947393-03-9 


\title{
Impressum
}

\author{
Direktorium Professor Dr. habil. Patrick Ulrich \\ Professor Dr. Ingo Scheuermann \\ Wissenschaftliche Projektleiter Professor Dr. habil. Patrick Ulrich \\ Professor Dr. habil. Stefan Behringer \\ Weitere beteiligte Personen Vanessa Frank \\ Anjuli Unruh \\ Herausgeber Professor Dr. habil. Patrick Ulrich \\ Professor Dr. Ingo Scheuermann \\ Hochschule Aalen \\ Aalener Institut für Unternehmensführung (AAUF) \\ Beethovenstr. 1 \\ D-73430 Aalen \\ Copyright @ 2020 by Aalener Institut für Unternehmensführung (AAUF) \\ Druck Aalen 2020 \\ Printed in Germany
}




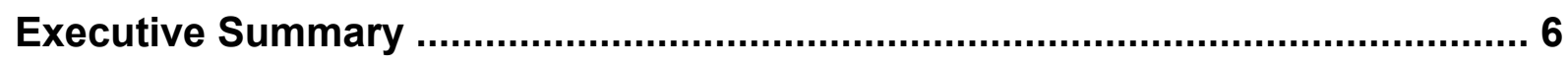

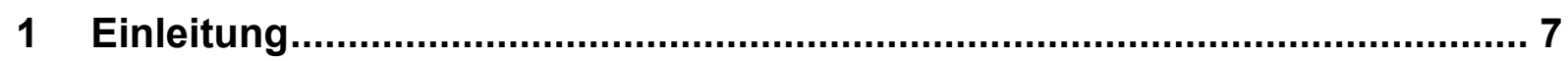

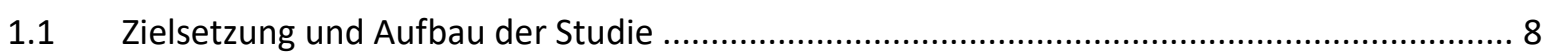

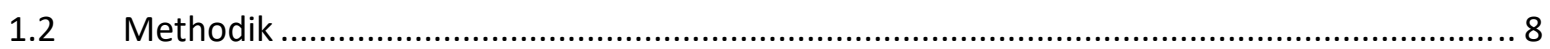

2 Allgemeine Angaben zum Unternehmen ................................................ 10

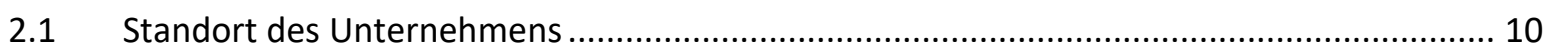

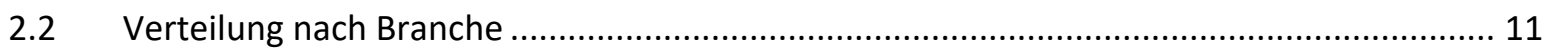

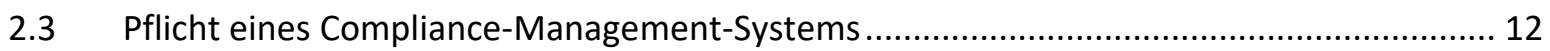

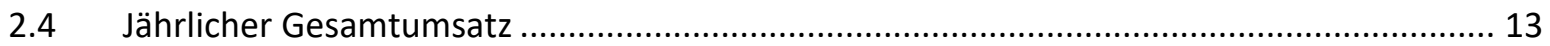

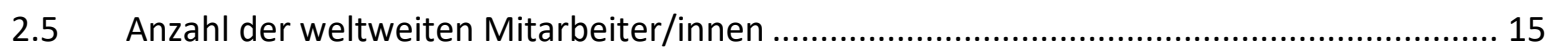

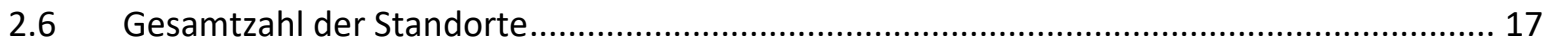

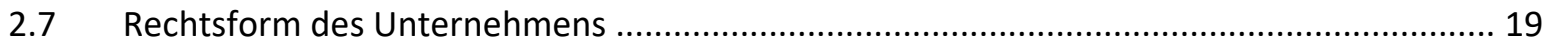

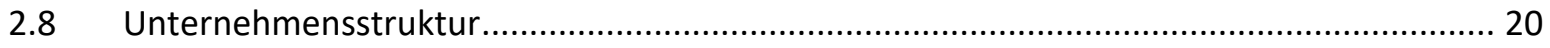

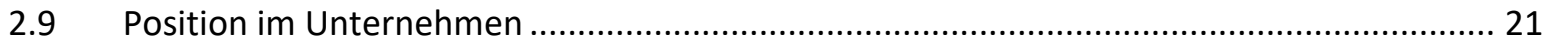

3 Fragen zum Compliance-Management..................................................... 22

3.1 Ansiedlung Compliance-Management in der Organisationsstruktur................................... 22

3.2 Formale Unterstellung des Compliance-Managements...................................................... 24

3.3 Die Compliance-Organisation als vorgesetzte Abteilung ................................................. 26

3.4 Existenz von Compliance-Management im Unternehmen ............................................... 27

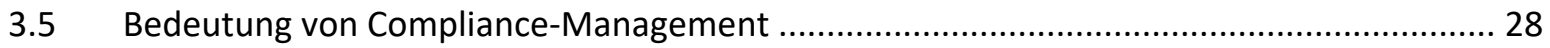

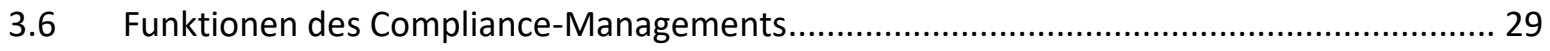

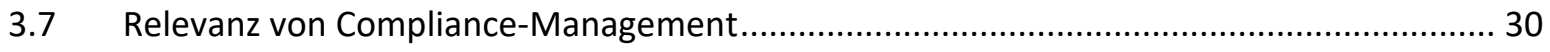

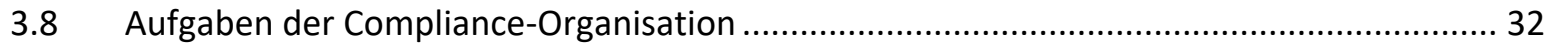

3.9 Instrumente zur Verankerung von Compliance …............................................................. 34

3.10 Rahmenwerk zur Entwicklung des Compliance-Managements ......................................... 36

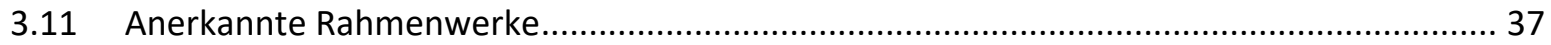

3.12 Zufriedenheit von Aspekten im Vergleich zum stärksten Wettbewerber ............................ 38

3.13 Zufriedenheit mit dem Compliance-Management im Unternehmen .................................. 40

3.14 Assoziation von Aufwandsaspekten mit Compliance-Management..................................... 41

3.15 Assoziation von Nutzenaspekte mit Compliance-Management ......................................... 42

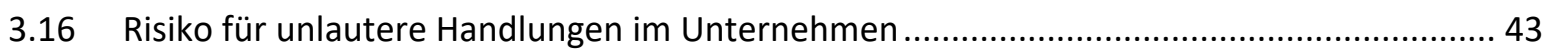

3.17 Einfluss von Compliance-Risiken auf das Unternehmen .................................................... 44

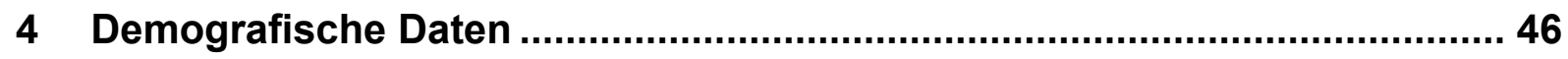

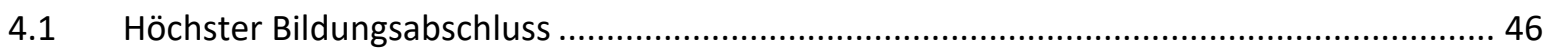

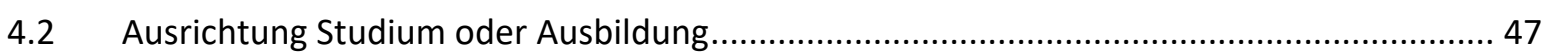




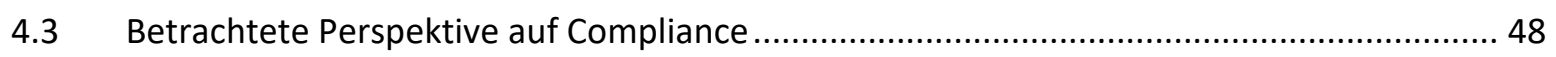

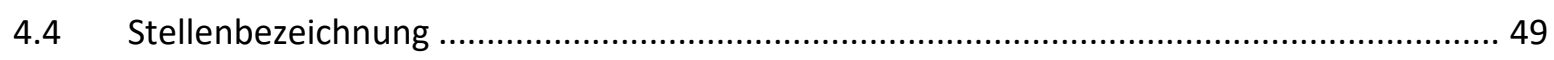

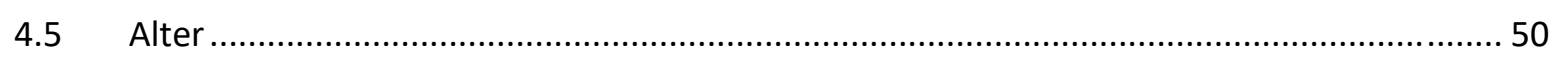

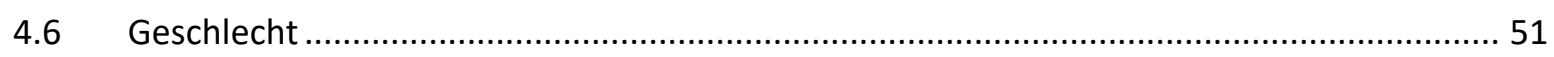

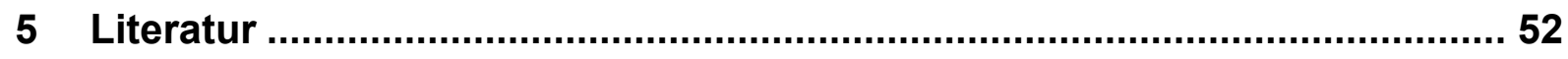

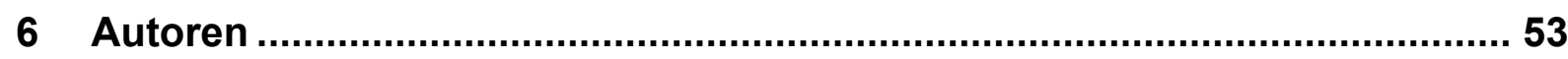


ABBILDUNG 1: TEILNAHME-, AUSSCHÖPFUNGS- UND RÜCKLAUFQUOTE................................... 9

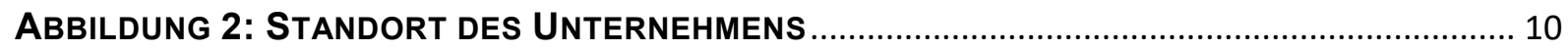

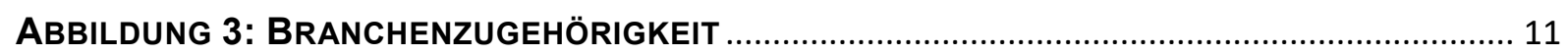

Abbildung 4: Pflicht eines Compliance-Management-Systems in DeR BRANChe ...... 12

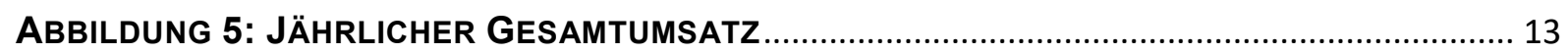

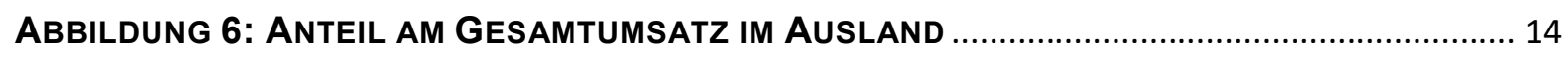

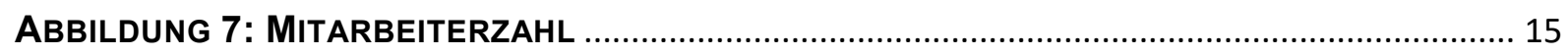

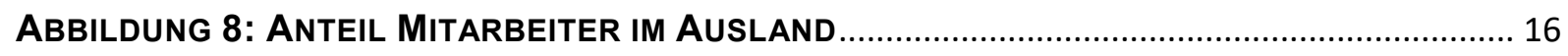

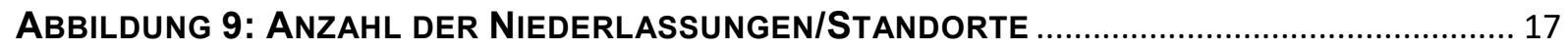

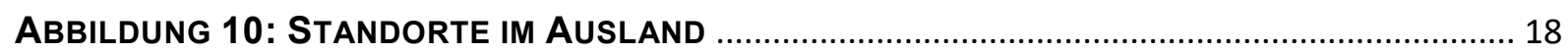

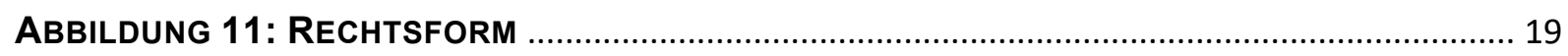

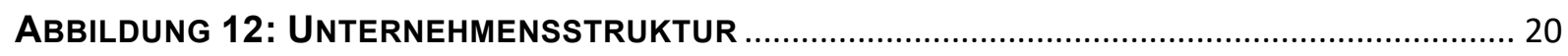

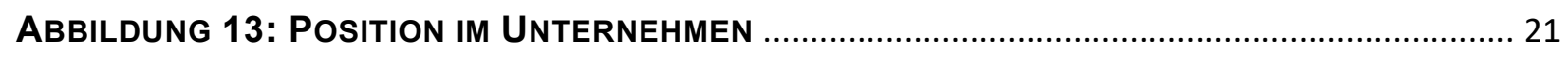

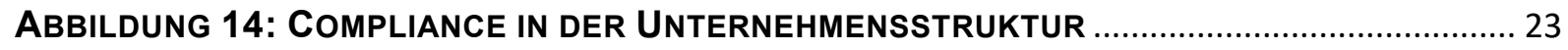

ABBILDUNG 15: FoRMALE UNTERSTELLUNG DER COMPLIANCE-ORGANISATION ..................... 25

ABBILDUNG 16: FoRMALE UNTERSTELLUNG ANDERER FUNKTIONEN ...................................... 26

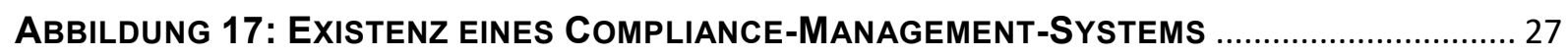

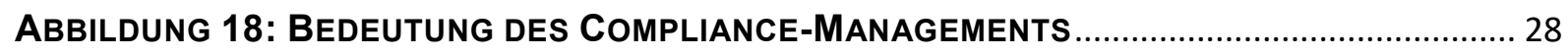

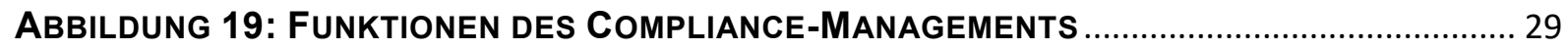

ABBILDUNG 20: RELEVANZ DES COMPLIANCE-MANAGEMENTS IN EINZELNEN

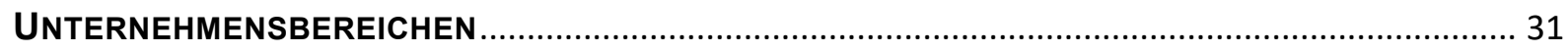

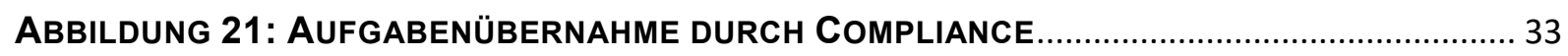

ABBILDUNG 22: INSTRUMENTE ZUR VERANKERUNG VON COMPLIANCE .................................. 35

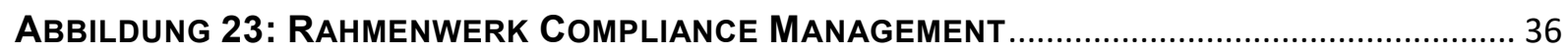

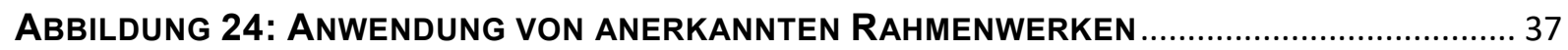

ABBILDUNG 25: ZUFRIEDENHEIT IM VERGLEICH ZUM STÄRKSTEN WETTBEWERBER ............... 39

ABBILDUNG 26: ZUFRIEDENHEIT MIT DEM EIGENEN CoMPLIANCE-MANAGEMENT.................... 40

ABBILDUNG 27: ASSOZIATION MIT AUFWANDSASPEKTEN.................................................... 41

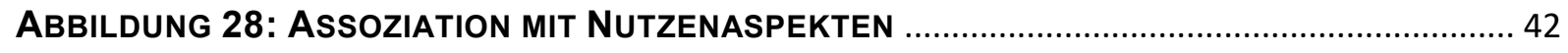

ABBILDUNG 29: EINSCHÄTZUNG DER GEFAHR VON UNLAUTEREN HANDLUNGEN .................... 43

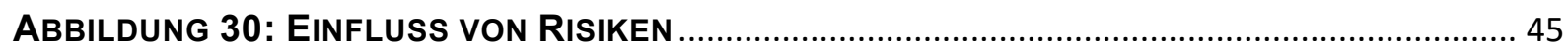

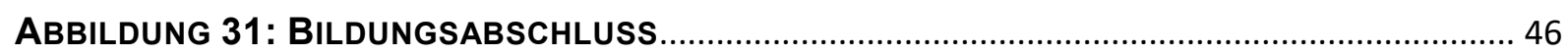

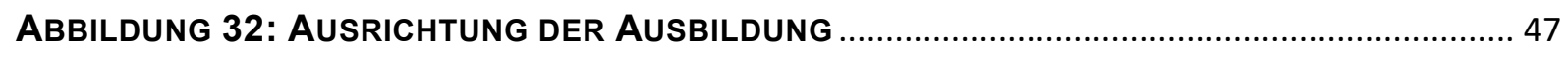

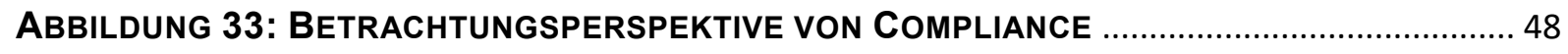

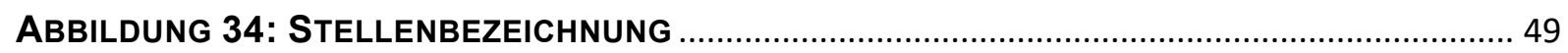

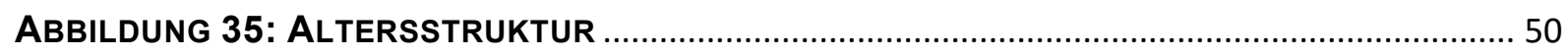

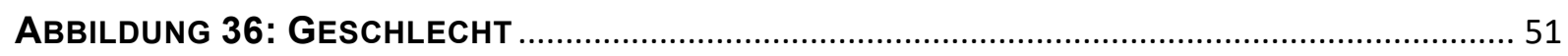




\section{Executive Summary}

Die vorliegende Untersuchung beschäftigt sich mit der Umsetzung und Implementierung von Compliance-Management in deutschen Unternehmen. Dazu wurden 142 Unternehmen anhand einer elektronischen Umfrage befragt. Der Fragebogen enthält 32 Fragen, diese sind in die drei Abschnitte „allgemeine Unternehmensfragen“, „Fragen zum Compliance Management" und „demographische Daten" unterteilt. Die Umfrage fokussiert sich hierbei besonders auf Fragestellungen hinsichtlich der organisatorischen Eingliederung, Funktionsweise, Aufgaben und Instrumente sowie der Bewertung des Compliance-Managements innerhalb der Unternehmen.

Etwas mehr als ein Drittel der befragten Unternehmen verfügt heute über ein Compliance-Management-System, während dies bei Unternehmen, die bisher kein geeignetes System vorweisen können, teilweise in Planung ist. Grundsätzlich ist Compliance-Management für die befragten Unternehmen von hoher Bedeutung und insbesondere für die Geschäftsführung und das Rechnungswesen bzw. Controlling von Relevanz. Des Weiteren ist das Compliance-Management in einem Großteil der Unternehmen auf der Ebene der Geschäftsführung oder als Stabstelle auf derselben Ebene integriert. Hauptsächliche Funktionen des Compliance-Managements sind die Prävention, Information, Kommunikation und Dokumentation. Unternehmen bedienen sich dabei formellen und informellen Instrumenten. So ist das ComplianceManagement bei den befragten Unternehmen häufig durch ein vorgegebenes Unternehmensleitbild, Richtlinien, Kodizes aber vor allem durch das Vorleben der Führungspersonen gekennzeichnet.

Ein Großteil der Befragten hat sich bei der Ausarbeitung ihres ComplianceManagements an kein formales internes oder externes Rahmenwerk angelehnt. Die Umsetzung geht für die meisten Unternehmen vor allem mit Verwaltungs-, Schulungsund Personalaufwänden einher. Demgegenüber stiftet Compliance für Unternehmen Nutzen im Hinblick auf die Reputation, Handlungssicherheit und den Schutz vor Haftungsrisiken. Mit der Umsetzung des Compliance-Managements sind die Unternehmen zu einem Großteil zufrieden, wobei die Unternehmen auch noch Verbesserungspotentiale sehen. 


\section{Einleitung}

Nahezu täglich wird in den Medien über Unternehmensskandale und wirtschaftskriminelle Handlungen berichtet (Behringer 2018, S. 31). Das Fehlverhalten von Unternehmen wird somit immer mehr in die Öffentlichkeit gestellt. Das Vertrauen in wirtschaftende Institutionen ist nicht zuletzt durch Wirtschaftsskandale von bspw. VW oder Siemens schwer erschüttert. Demzufolge ist das Thema Wirtschaftskriminalität weltweit in das Bewusstsein der Gesellschaft gerückt und der Bereich Compliance, verstanden als Summe der Maßnahmen, die ein Unternehmen zur Integrität ergreift, gewinnt zunehmend an Bedeutung.

Die Gefahr für Unternehmen selbst im Mittelpunkt eines Skandals zu stehen, nimmt durch die Heterogenität der möglichen Wirtschaftsdelikte (Schuchter 2012, S. 42), die Entdeckungswahrscheinlichkeit und die Strafhöhe, welche durch die wachsende Anzahl an Überwachung und Regelwerken weiter ansteigen, zu. Nicht selten führt die Aufnahme von Ermittlungen zu immensen Schäden, die nicht nur aus hohen Geldbeträgen bestehen, sondern beispielsweise durch Schädigung der Reputation des Unternehmens, auch immateriell sein können (Bundeslagebericht Wirtschaftskriminalität, 2018, S. 5). Durch die erhöhte Aufmerksamkeit der breiten Öffentlichkeit wird von den Unternehmen immer mehr gefordert die geltenden Gebote einzuhalten und Verbote zu kennen und zu achten. Als Antwort auf die Herausforderungen, vor denen Organisationen in diesem Zusammenhang stehen, ist ein funktionierendes Compliance-Management-System unabdingbar (Geissler 2004).

„[Der Begriff Compliance] umfasst die Gesamtheit der Maßnahmen, die ein Unternehmen ergreift, um sicherzustellen, dass die extern vorgegebenen Regeln (seien es Gesetze oder andere verpflichtende Regeln) eingehalten werden. Hinzu kommt, dass sich Unternehmen selbst Regeln geben, deren Maßstab ein ethisches und verantwortliches Handeln ist. Auch die Ausarbeitung dieser Regeln und die Maßnahmen, die zu ihrer Einhaltung ergriffen werden, sollen unter dem Begriff Compliance subsumiert werden." (Behringer 2018, S. 35). Das heißt, dass Organe und Unternehmen mit dem geltenden Recht sowie den intern auferlegten Regularien übereinstimmen müssen. Der Deutsche Corporate Governance Kodex definiert seit 2007 eine Art Legaldefinition für Compliance, in der steht: „Grundsatz 5: Der Vorstand hat für die Einhaltung der gesetzlichen Bestimmungen und der internen Richtlinien zu 
sorgen und wirkt auf deren Beachtung im Unternehmen hin (Compliance)." (Regierungskommission Deutscher Corporate Governance Kodex 2019).

Da Compliance als Teil einer guten und verantwortungsvollen Unternehmensführung eine bedeutende Rolle einnimmt, hat das Aalener Institut für Unternehmensführung (AAUF) in Zusammenarbeit mit dem Institut für Finanzdienstleistungen (IFZ) an der Hochschule Luzern eine Studie zu Compliance-Management in deutschen Unternehmen durchgeführt. Insgesamt beteiligten sich 142 Unternehmen an der Studie.

\subsection{Zielsetzung und Aufbau der Studie}

Ziel der Studie ist es, ein aktuelles Bild über den Implementierungsstand von Compliance-Management in deutschen Unternehmen zu gewinnen. Hierbei stehen insbesondere die Ausgestaltung sowie Effektivität des Compliance-Managements im Mittelpunkt. Insgesamt enthielt der Fragebogen 32 Fragen, die in drei Abschnitte unterteilt waren. Zunächst wurden allgemeine Fragen zum Unternehmen abgefragt, gefolgt von Fragen zur organisatorischen Eingliederung, Funktionsweise, Aufgaben und Instrumente sowie die Bewertung des Compliance-Managements. Am Ende des Fragebogens wurden demographische Daten zum Antwortenden abgefragt.

\subsection{Methodik}

Die Datenerhebung erfolgte mit Hilfe eines standardisierten Online-Fragebogens. Dieser enthielt offene sowie geschlossene Fragen. Zur Überprüfung des Fragebogens wurde zunächst ein Pre-Test mit mehreren Probanden durchgeführt. Im Anschluss erfolgte die tatsächliche Befragung im Zeitraum vom 04.02.2020 bis zum 28.02.2020. Hierfür wurden vorab mit Hilfe der Datenbank Nexis per Zufallsprinzip E-Mail-Adressen von deutschen Unternehmen generiert. Am 18.02.2020 wurde zusätzlich eine Erinnerungsmail an die Probanden versendet.

Insgesamt wurden 14.561 Unternehmen per E-Mail kontaktiert, wobei 1.214 E-Mails nicht zugestellt werden konnten. Somit erhielten 13.347 Unternehmen den Link zur Onlineumfrage. Der Onlinefragebogen wurde im Befragungszeitraum 185-mal aufgerufen, was einer Teilnahmequote von 1,39 Prozent entspricht. 142 Unternehmen beantworteten die gestellten Fragen, wobei 51 Unternehmen die Umfrage vorzeitig 
abgebrochen haben (Ausschöpfungsquote: 76,76 Prozent). Die Stichprobengröße beläuft sich somit auf 91 Unternehmen und die Rücklaufquote auf 0,68 Prozent.

In diesem Zusammenhang ist anzumerken, dass es bei einzelnen Fragegestellungen dennoch zu unterschiedlichen Nennungen kommen kann, da der partielle Antwortausfall (Item-Non-Response) im vorliegenden Ergebnisbericht nicht berücksichtigt wurde. Dies liegt daran, dass bei der Gestaltung des Fragebogens bewusst auf das Festlegen von Pflichtfragen verzichtet wurde, da teilweise sehr themenspezifische und sensible Daten abgefragt wurden. Die Auswertung der Daten erfolgte mittels Microsoft Excel.

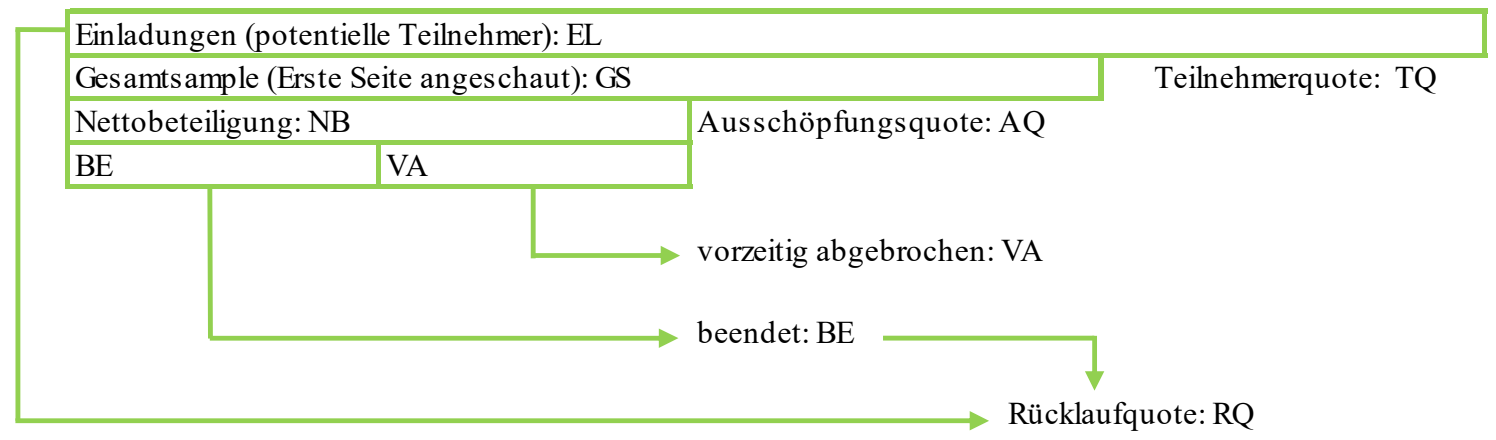

\begin{tabular}{|c|c|c|c|c|c|c|c|c|}
\hline & EL & \multicolumn{1}{l|}{ GS } & GS/EL=TQ & NB & NB/GS=AQ & VA & BE & BE/EL=RQ \\
\hline Quoten & 13.347 & 185 & $1,39 \%$ & 142 & $76,76 \%$ & 51 & 91 & $0,68 \%$ \\
\hline
\end{tabular}

ABbiLdung 1: TEILNAHME-, AUSSCHÖPFUngS- Und RÜCKLAUFQUOTE

Abbildung 1 veranschaulicht die Berechnung der Teilnahme-, Ausschöpfungs- und Rücklaufquote. 


\section{Allgemeine Angaben zum Unternehmen}

In diesem Abschnitt sind Details zu den teilnehmenden Unternehmen enthalten, wie bspw. Branchenverteilung, Umsatz und Mitarbeiteranzahl.

\subsection{Standort des Unternehmens}

Diese Frage hatte zum Ziel, herauszufinden, wo die befragten Unternehmen ihren Standort haben.

98 Prozent der Befragten geben an, dass sich ihr Unternehmen in Deutschland befindet. Einen Standort in der Schweiz geben 2 Prozent der Probanden an.

\section{Standort}

$[\mathrm{N}=131]$

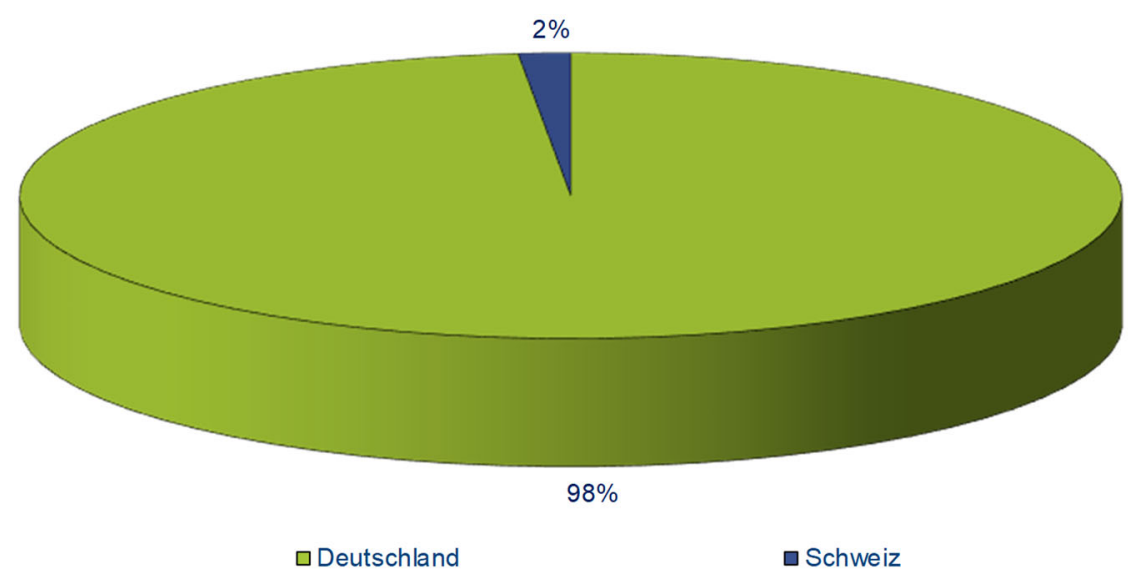




\subsection{Verteilung nach Branche}

Um die Ergebnisse besser kategorisieren zu können, wurden die Probanden gebeten, die Branchenzugehörigkeit ihres Unternehmens anzugeben.

Die Branchenzugehörigkeit der Unternehmen gestaltet sich wie folgt: 35 Prozent der Unternehmen sind in der Industrie tätig, 35 Prozent im Dienstleistungssektor und 8 Prozent im Gesundheitswesen. 5 Prozent der befragten Unternehmen gehören der Branche Finanzdienstleistungen, also bspw. Banken und Versicherungen an und die verbleibenden 17 Prozent fallen unter „Sonstige/Keine Angaben“.

\section{Branchenzugehörigkeit}

[N=132]

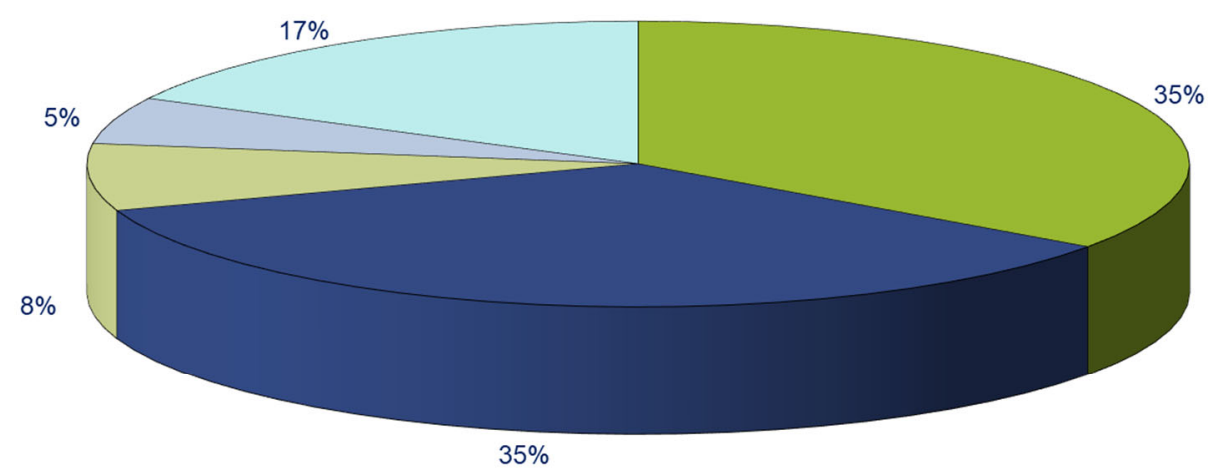

口Industrie

口Dienstleistungen

$\square$ Gesundheitswesen

口Finanzdienstleistungen

$\square$ Sonstige 


\subsection{Pflicht eines Compliance-Management-Systems}

Diese Frage diente dazu herauszufinden, in welchen der befragten Unternehmen ein Compliance-Management-System gesetzlich vorgeschrieben ist. Dies betrifft vor allem den Finanzdienstleistungssektor. Ausserdem gibt es gesetzliche Verpflichtungen bei Tochtergesellschaften ausländischer Konzerne.

Bei 11 Prozent der befragten Probanden ist die Einführung eines ComplianceManagement-Systems in der Branche gesetzlich vorgeschrieben. Bei 89 Prozent der Befragten besteht für die betreffende Branche keine gesetzliche Verpflichtung zur Einführung eines Compliance-Management-Systems.

Pflicht eines Compliance-Management-Systems in der Branche [N=133]

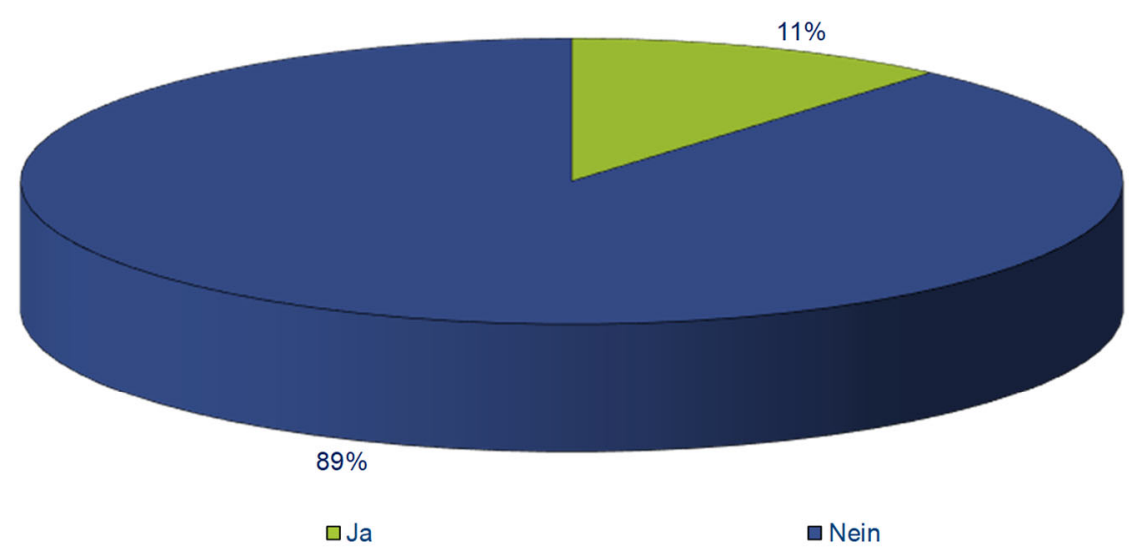




\subsection{Jährlicher Gesamtumsatz}

Ziel dieser Frage war es, die befragten Unternehmen nach ihrem jährlichen Gesamtumsatz zu kategorisieren.

4 Prozent der befragten Unternehmen erwirtschaften einen jährlichen Umsatz unter 2 Mio. Euro, 19 Prozent einen Umsatz zwischen 2 Mio. und 10 Mio. Euro und 55 Prozent einen Umsatz zwischen 10 Mio. und 50 Mio. Euro. 16 Prozent erzielen im Jahr einen Umsatz zwischen 50 Mio. und 500 Mio. Euro und 5 Prozent von mehr als 500 Mio. Euro.

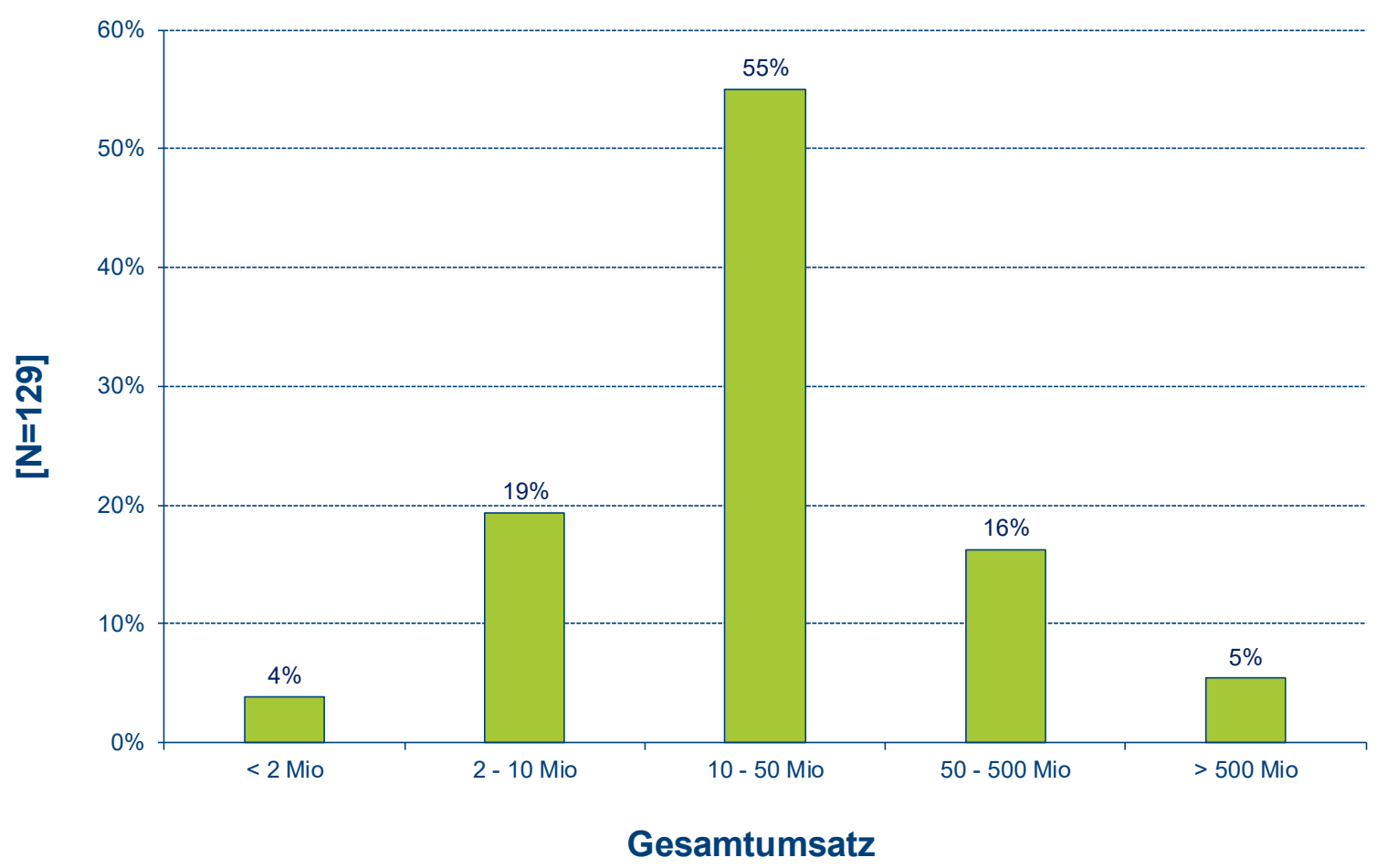


Der Anteil des jährlichen Gesamtumsatzes, der auf das Ausland entfällt beträgt bei 41 Prozent der befragten Unternehmen 0 Prozent, bei 23 Prozent zwischen 0 und 25 Prozent und bei weiteren 23 Prozent zwischen 25 und 50 Prozent. Bei 6 Prozent der Befragten beträgt der Auslandsanteil am Jahresumsatz zwischen 50 und 75 Prozent und bei weiteren 6 Prozent zwischen 75 und 100 Prozent.

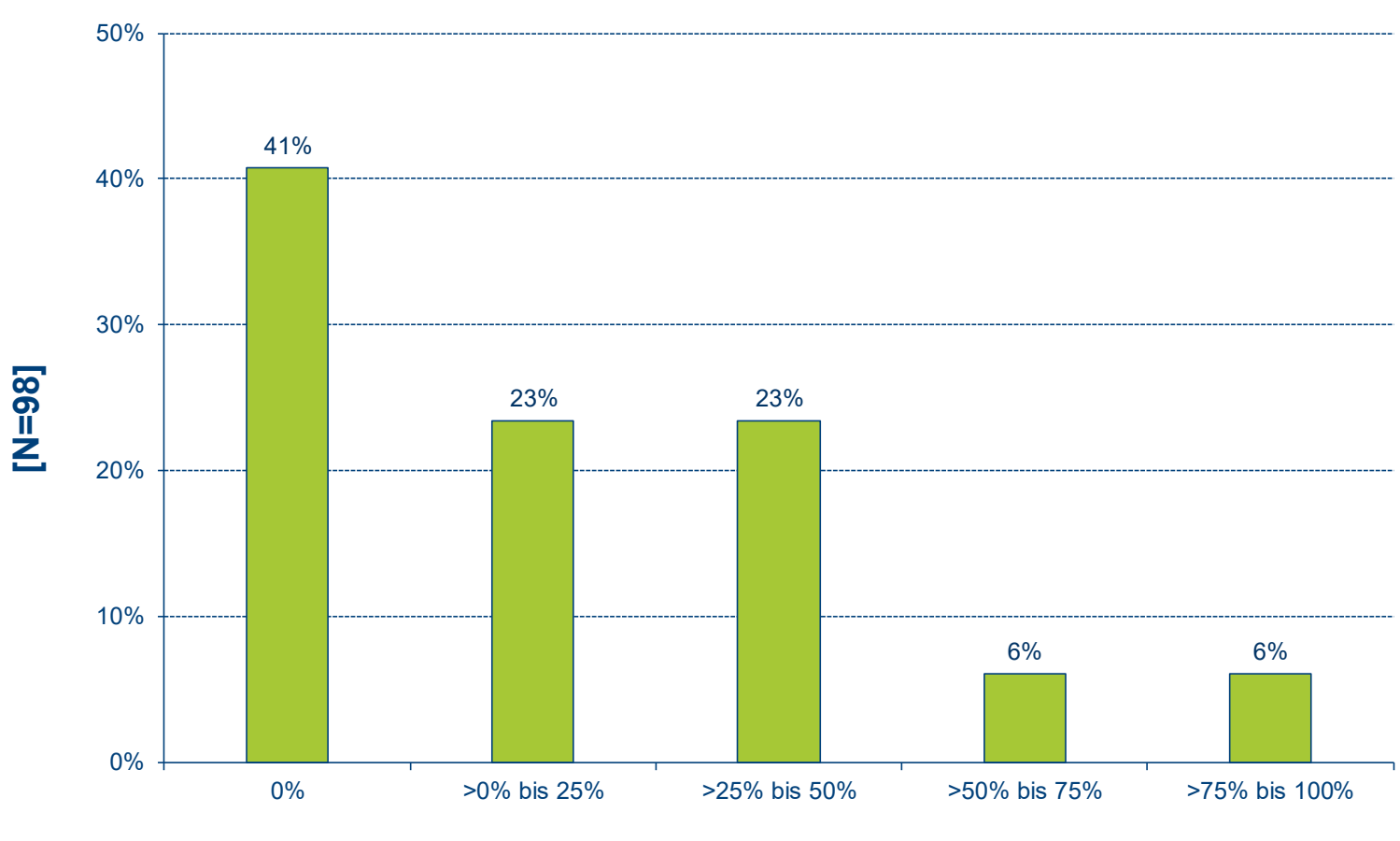

Anteil Gesamtumsatz im Ausland 


\subsection{Anzahl der weltweiten Mitarbeiter/innen}

Um die befragten Unternehmen nach ihrer Größe zu kategorisieren, wurden sie gebeten, die Anzahl der Mitarbeiter insgesamt, sowie den Anteil der Mitarbeiter im Ausland anzugeben.

Kein Unternehmen beschäftigt weniger als 10 Mitarbeiter/innen. 5 Prozent der Unternehmen beschäftigen weltweit zwischen 10 und 50 Mitarbeiter/innen, 73 Prozent zwischen 50 und 250 Mitarbeiter/innen und 18 Prozent zwischen 250 und 2.500 Mitarbeiter/innen. Bei 4 Prozent der Unternehmen arbeiten weltweit mehr als 2.500 Mitarbeiter/innen.

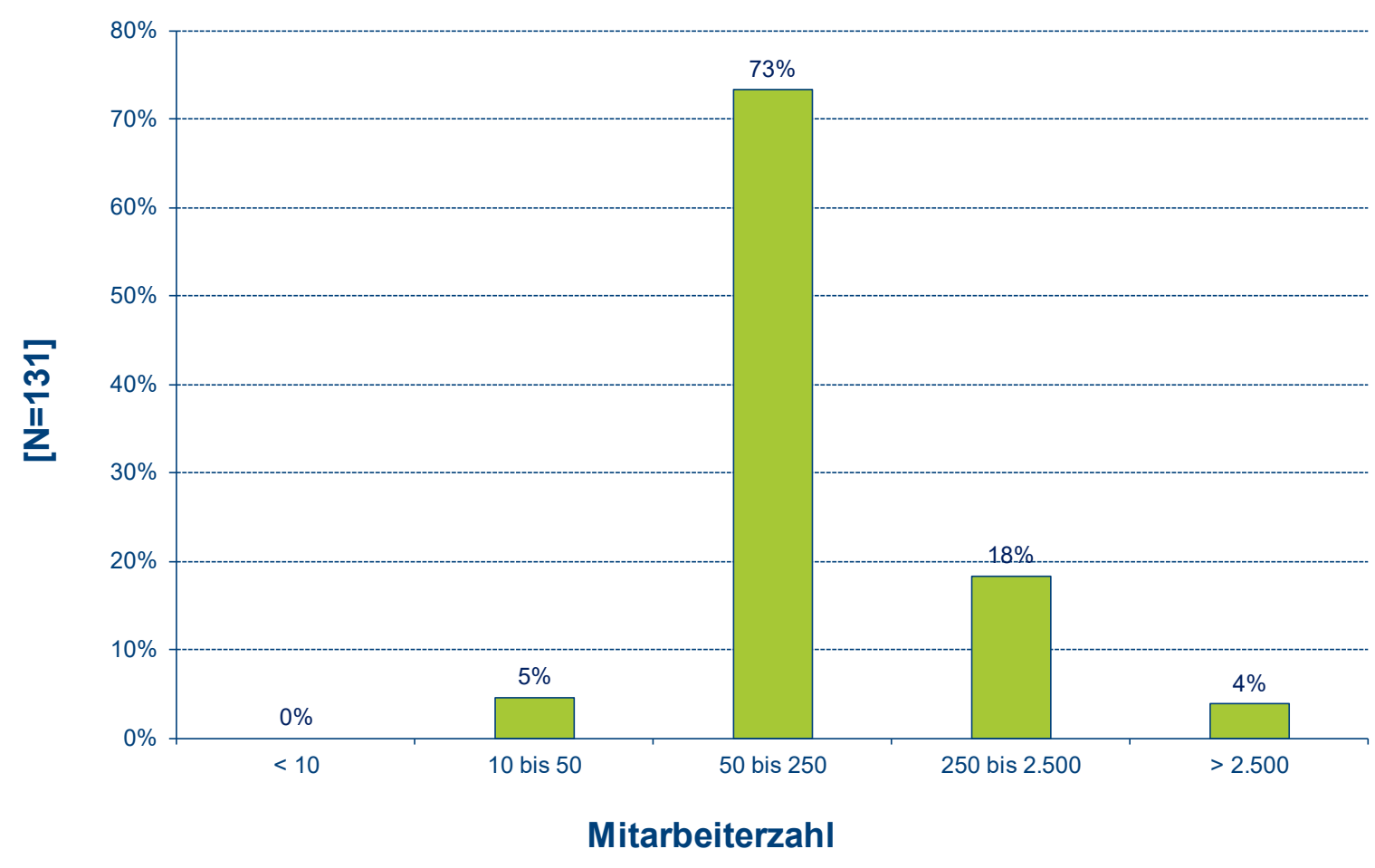

AbBildung 7: MitARBeIteRZAHL 
76 Prozent der befragten Unternehmen beschäftigen keine Mitarbeiter im Ausland. Bei 14 Prozent der befragten Unternehmen beläuft sich der Anteil, der im Ausland beschäftigen Mitarbeiter auf zwischen 0 und 25 Prozent und bei 8 Prozent zwischen 25 und 50 Prozent. Keine der Befragten gab an, dass zwischen 50 und 75 Prozent der Mitarbeiter im Ausland beschäftigt sind, während 2 Prozent angeben, dass zwischen 75 und 100 Prozent der Mitarbeiter im Ausland tätig sind.

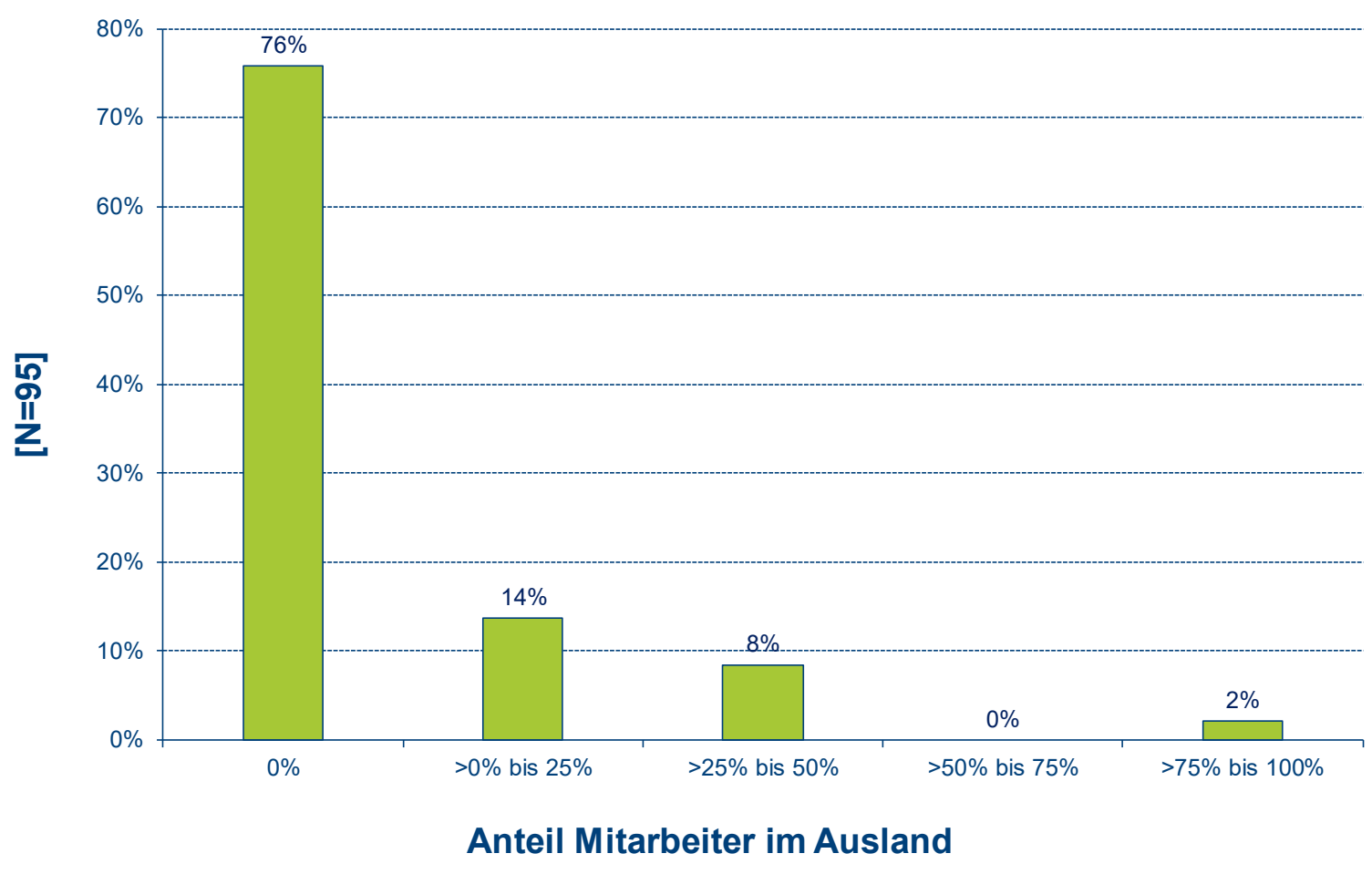

ABbiLdung 8: ANTEIL MITARBEITER IM AUSLAND 


\subsection{Gesamtzahl der Standorte}

In dieser Frage wurden die Befragten gebeten, die Anzahl der Standorte und Niederlassungen sowohl insgesamt als auch im Ausland anzugeben.

60 Prozent der befragten Unternehmen haben 1 bis 2 Standorte, 18 Prozent haben zwischen 3 und 5 Standorte und 9 Prozent zwischen 6 und 10 Standorte. Mehr als 10 Standorte haben 14 Prozent der befragten Unternehmen.

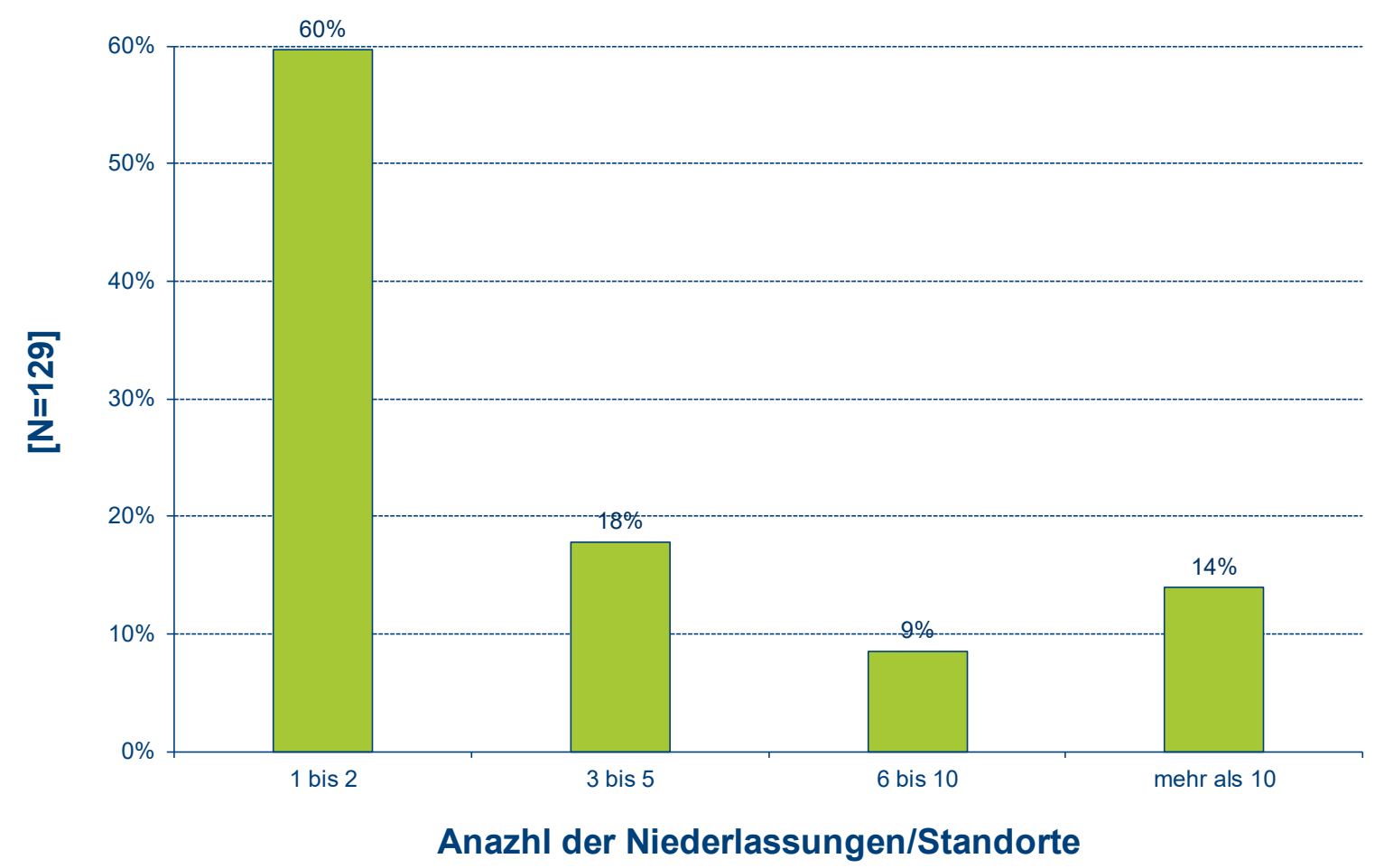

Abbildung 9: Anzahl der NiederLAssungen/StAndorte 
82 Prozent der befragten Unternehmen geben an, dass sie keinen Standort im Ausland haben. Bei 4 Prozent der Unternehmen sind zwischen 0 und 25 Prozent der Standorte im Ausland angesiedelt. Einen Standortauslandsanteil zwischen 25 und 50 Prozent geben 8 Prozent der befragten Unternehmen an, während 4 Prozent einen Anteil zwischen 50 und 75 Prozent angeben. 2 Prozent der befragten Unternehmen geben an, dass zwischen 75 und 100 Prozent der Standorte im Ausland angesiedelt sind.

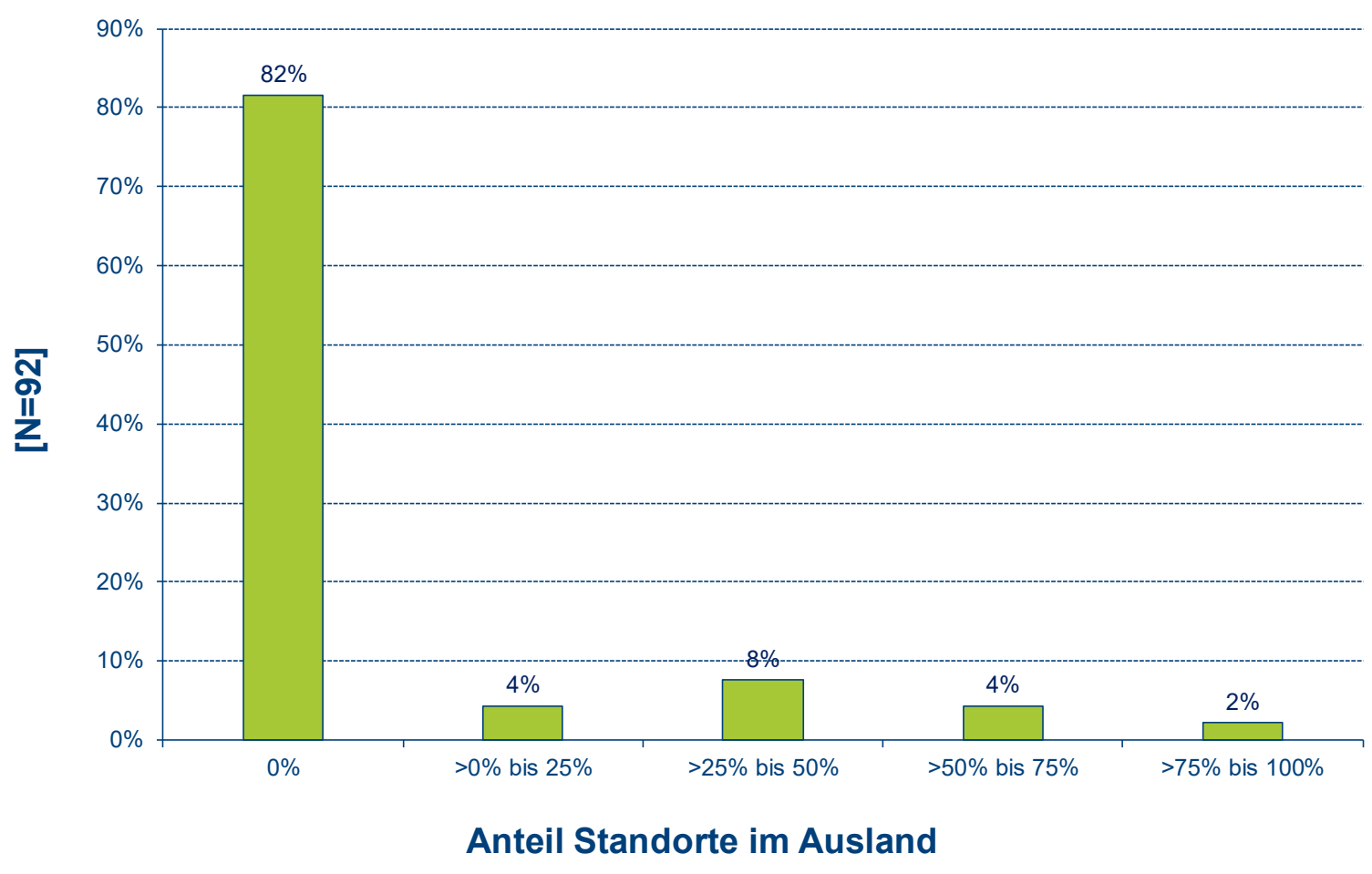

AbBildung 10: StANDORTE IM AUSLAND 


\subsection{Rechtsform des Unternehmens}

Diese Frage diente dazu, herauszufinden welcher Rechtsform die jeweiligen Unternehmen angehören.

60 Prozent der befragten Unternehmen werden in der Rechtsform der $\mathrm{GmbH}$ geführt, eine $\mathrm{GmbH} \&$ Co. KG sind 17 Prozent und eine AG 10 Prozent der Befragten. 1 Prozent der befragten Unternehmen führen ihr Unternehmen in der Rechtsform der KG und 12 Prozent in einer sonstigen Rechtsform.

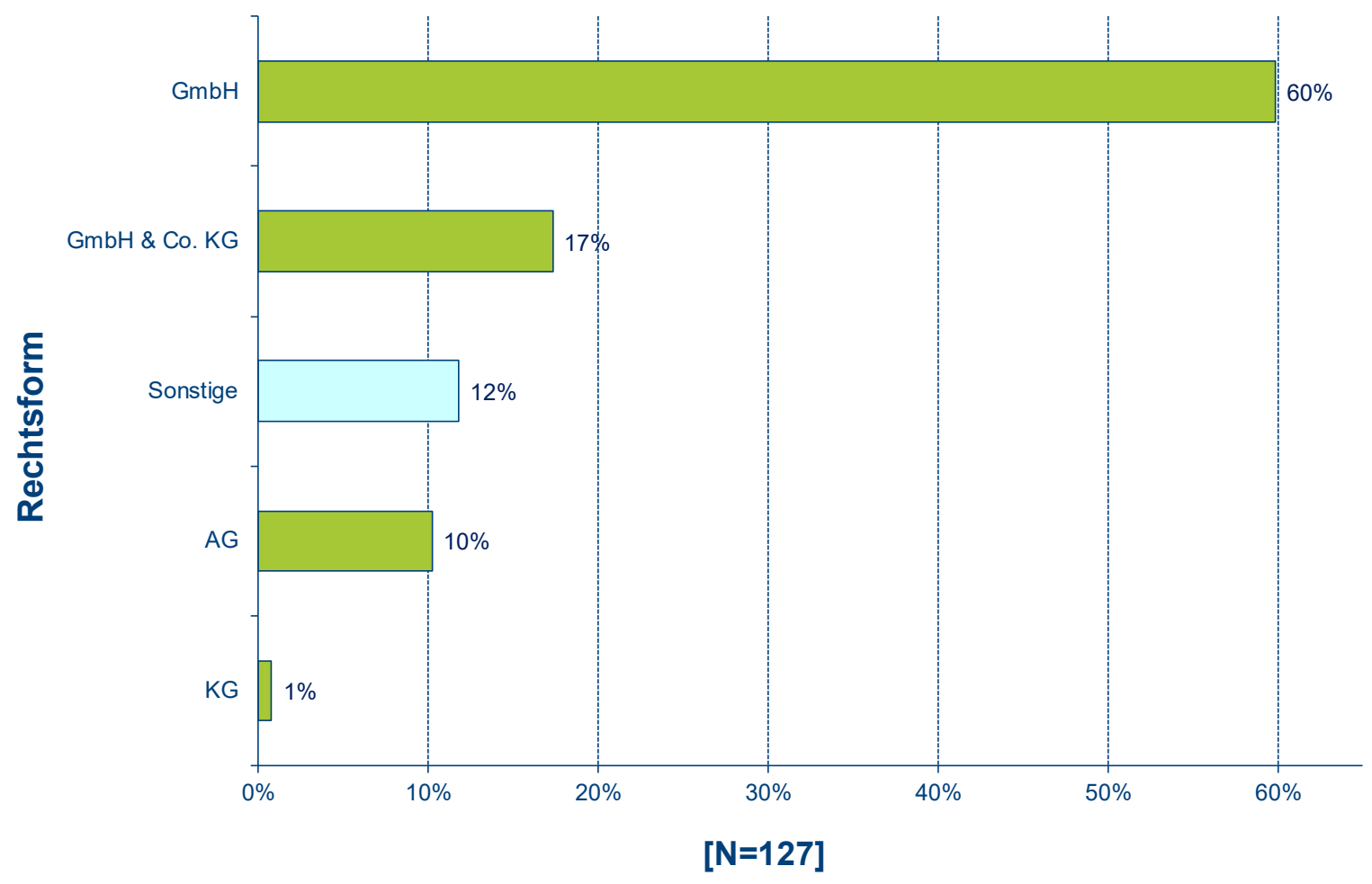




\subsection{Unternehmensstruktur}

Diese Frage hatte das Ziel, herauszufinden, welche Unternehmensstruktur die befragten Unternehmen haben.

56 Prozent $^{1}$ der befragten Unternehmen geben an, dass ein Gesellschafter bzw. Eigentümer Sprecher der Geschäftsführung ist, während 51 Prozent $^{2}$ angeben, ein Familienunternehmen zu sein. 23 Prozent $^{3}$ der befragten Unternehmen sind strukturell als Tochtergesellschaft und 14 Prozent ${ }^{4}$ als Muttergesellschaft unternehmerisch tätig. 4 Prozent ${ }^{5}$ der befragten Unternehmen sind börsennotiert.

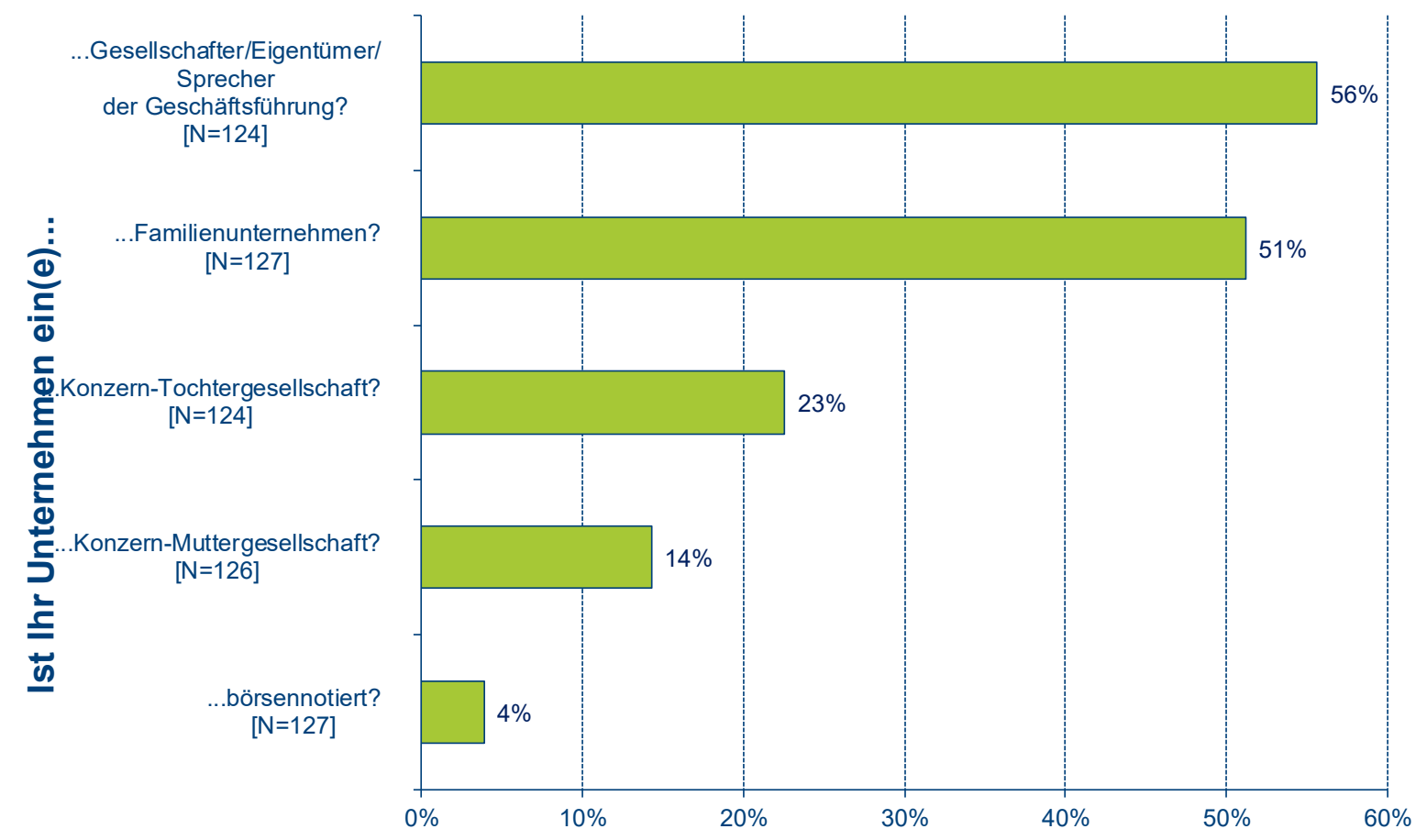

${ }^{1}$ Grundgesamtheit der Nennungen: 124.

${ }^{2}$ Grundgesamtheit der Nennungen: 127.

${ }^{3}$ Grundgesamtheit der Nennungen: 124.

${ }^{4}$ Grundgesamtheit der Nennungen: 126.

${ }^{5}$ Grundgesamtheit der Nennungen: 127. 


\subsection{Position im Unternehmen}

Diese Frage diente dazu, herauszufinden, welche Position der antwortende Mitarbeiter im Unternehmen innehat.

78 Prozent der befragten Probanden sind angestellte Manager, während es sich bei den verbleibenden 22 Prozent um den Eigentümer bzw. Gesellschafter des Unternehmens handelt.

\section{Position im Unternehmen}

$[\mathrm{N}=124]$

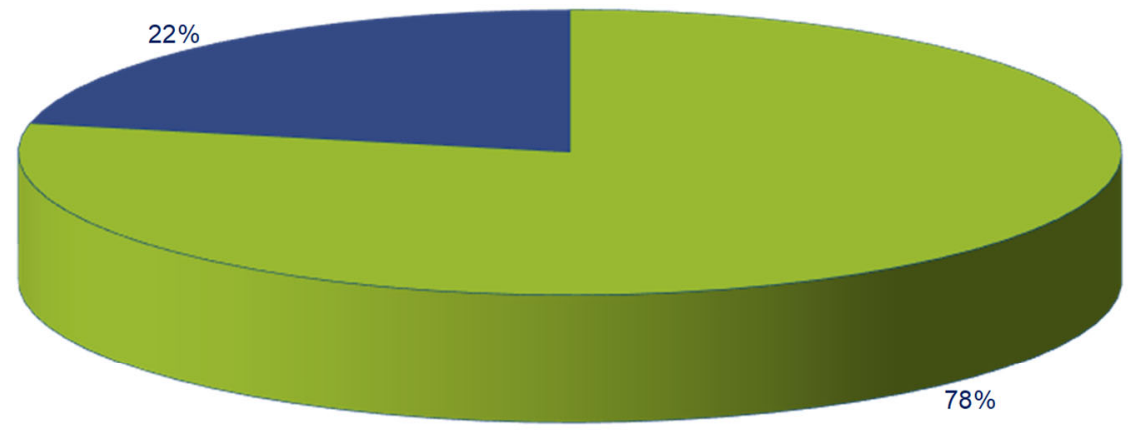

$\square$ Manager(in) (angestellt)

- Eigentümer(in)/Gesellschafter(in) 


\section{Fragen zum Compliance-Management}

Die nachfolgenden Kapitel thematisieren die Bedeutung des ComplianceManagements in dem Unternehmen.

\subsection{Ansiedlung Compliance-Management in der Organisationsstruktur}

Anhand dieser Frage wurde ermittelt, wo die Compliance-Organisation formal innerhalb der Organisation angesiedelt ist.

Bei 32 Prozent der befragten Unternehmen ist das Compliance-Management auf höchster Leitungsebene angesiedelt. Sprich der Compliance-Verantwortliche ist Mitglied des Vorstands bzw. der Geschäftsführung. Bei 31 Prozent der Befragten ist das Compliance-Management als Stabsstelle/-abteilung auf der Leitungsebene und bei 14 Prozent direkt unterhalb der Leitungsebene mit zentraler Leitungsbefugnis für dezentrale Compliance-Einheiten angeordnet. Das Compliance-Management ist in 7 Prozent der befragten Unternehmen unterschiedlichen Fachabteilungen zugeordnet. Bei 6 Prozent der befragten Unternehmen ist das Compliance Management einer Organisationseinheit unterstellt. Weitere 6 Prozent der Befragten geben an, dass das Compliance-Management einer sonstigen Organisationseinheit des Unternehmens unterstellt ist. Als gleichrangige Abteilung neben anderen ist Compliance-Management bei 4 Prozent der befragten Unternehmen angeordnet. 


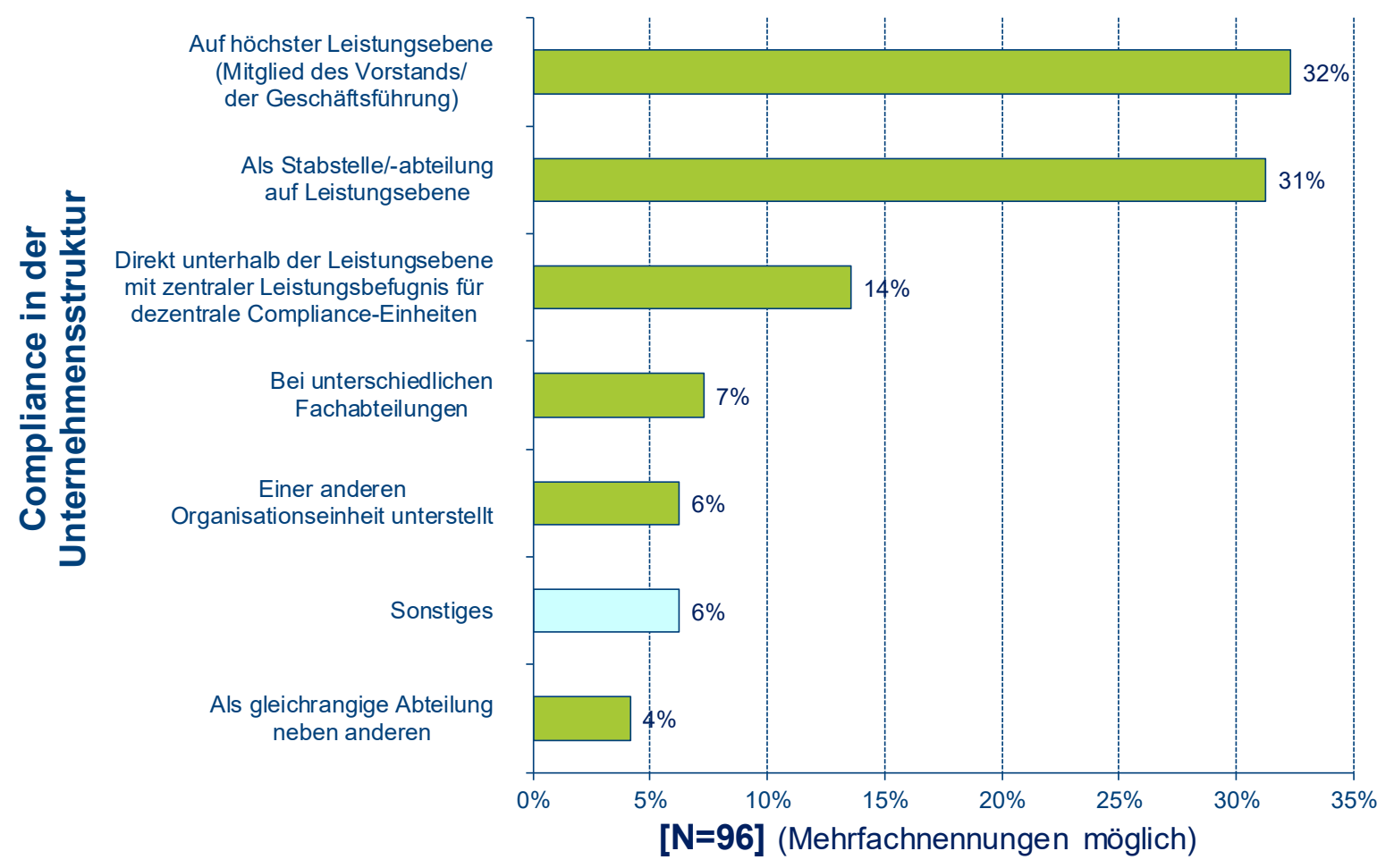

ABBILDUNG 14: COMPLIANCE IN DER UNTERNEHMENSSTRUKTUR 


\subsection{Formale Unterstellung des Compliance-Managements}

Im Falle, dass das Compliance-Management nicht direkt der Geschäftsführung oder als Stabsstelle auf dieser Leistungsebene organisatorisch verankert wurde, diente diese Frage dazu, herauszufinden, welcher anderen Organisationseinheit das Compliance-Management stattdessen unterstellt ist.

Die Mehrzahl der Befragten, 15 Prozent, gibt an, dass die Compliance-Organisation anderen als den angegebenen Einheiten unterstellt ist. An dieser Stelle konnten individuelle Angaben anhand eines Freitextes angegeben werden. Am häufigsten wurde angegeben, dass die Compliance-Organisation direkt der Geschäftsleitung bzw. dem CEO oder der Organisationsentwicklung unterstellt ist. Des Weiteren wird häufig angegeben, dass die Compliance-Organisation keiner anderen Einheit unterstellt ist. Dem Qualitätsmanagement wird das Compliance-Management in 9 Prozent und dem Datenschutz in 8 Prozent der befragten Unternehmen unterstellt. 7 Prozent der befragten Unternehmen geben an, dass das Compliance-Management der Einheit Recht zugeordnet wird, während 6 Prozent angeben, dass das ComplianceManagement dem Risikomanagement unterstellt ist. Die Leitung des ComplianceManagements wird in 4 Prozent der Unternehmen auf das Rechnungswesen übertragen. 2 Prozent der Befragten geben an, dass das Compliance-Management in ihrem Unternehmen der Arbeitssicherheit unterstellt ist. 


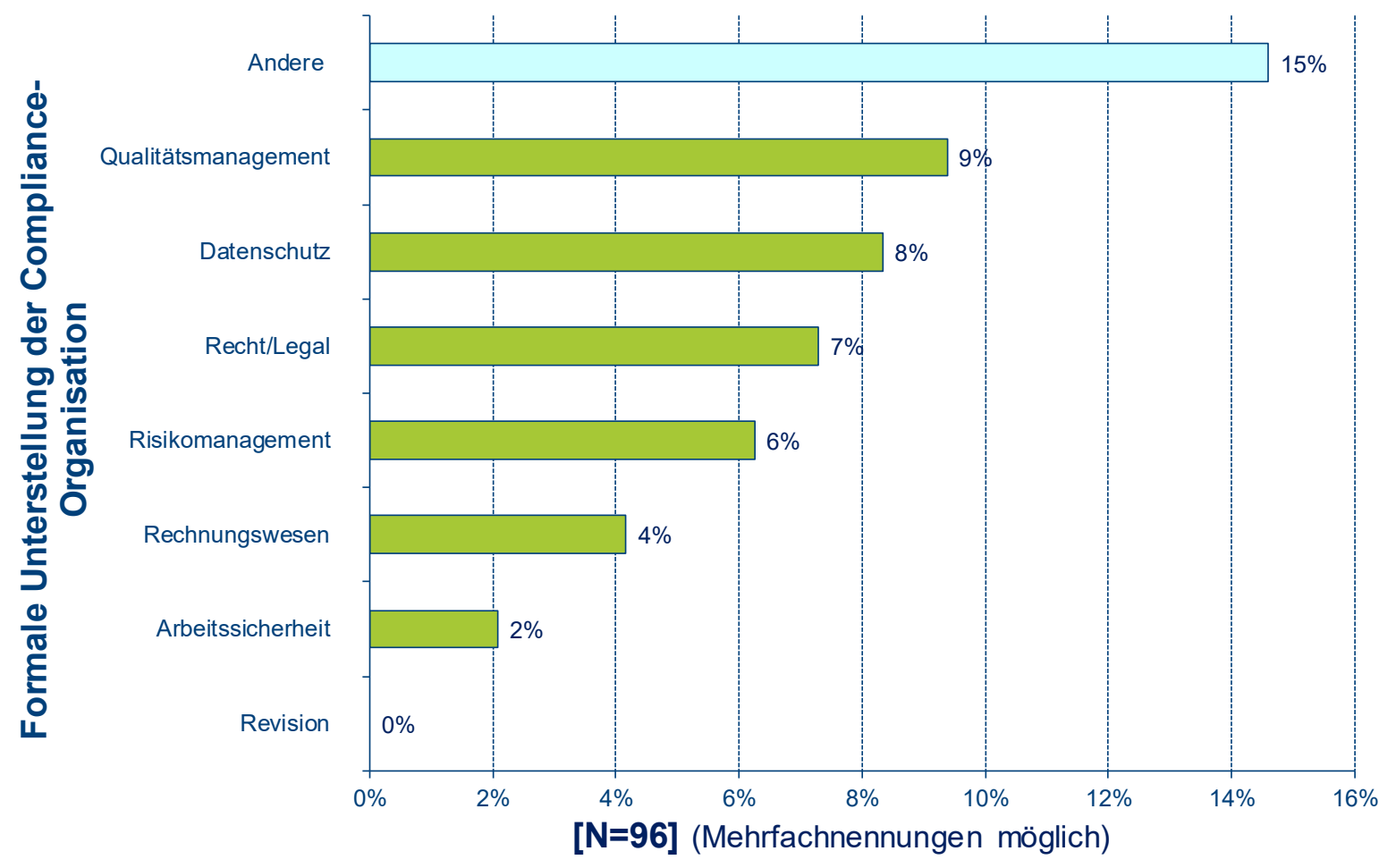

ABbildung 15: Formale UnTERStellung DeR CoMpliance-ORganisation 


\subsection{Die Compliance-Organisation als vorgesetzte Abteilung}

Diese Frage hatte das Ziel, herauszufinden, welche anderen Funktionen der Compliance-Organisation unterstellt sind.

Die Compliance-Organisation ist in 17 Prozent der Unternehmen dem Qualitätsmanagement, in 15 Prozent dem Datenschutz und in 14 Prozent anderen Funktionen 6 übergeordnet. Unter diesen 14 Prozent wird am häufigsten angegeben, dass der Compliance-Organisation entweder die IT-Sicherheit oder keine weitere Einheit unterstellt ist. Das Risikomanagement wird bei 11 Prozent, die Funktion Recht bzw. Legal bei 9 Prozent der befragten Unternehmen dem Compliance-Management untergeordnet. Weitere 9 Prozent der befragten Unternehmen haben angegeben, dass die Arbeitssicherheit und 8 Prozent, dass das Rechnungswesen dem ComplianceManagement unterstellt ist. Die Revision überträgt ihre Leitung dem ComplianceManagement in 7 Prozent der befragten Unternehmen.

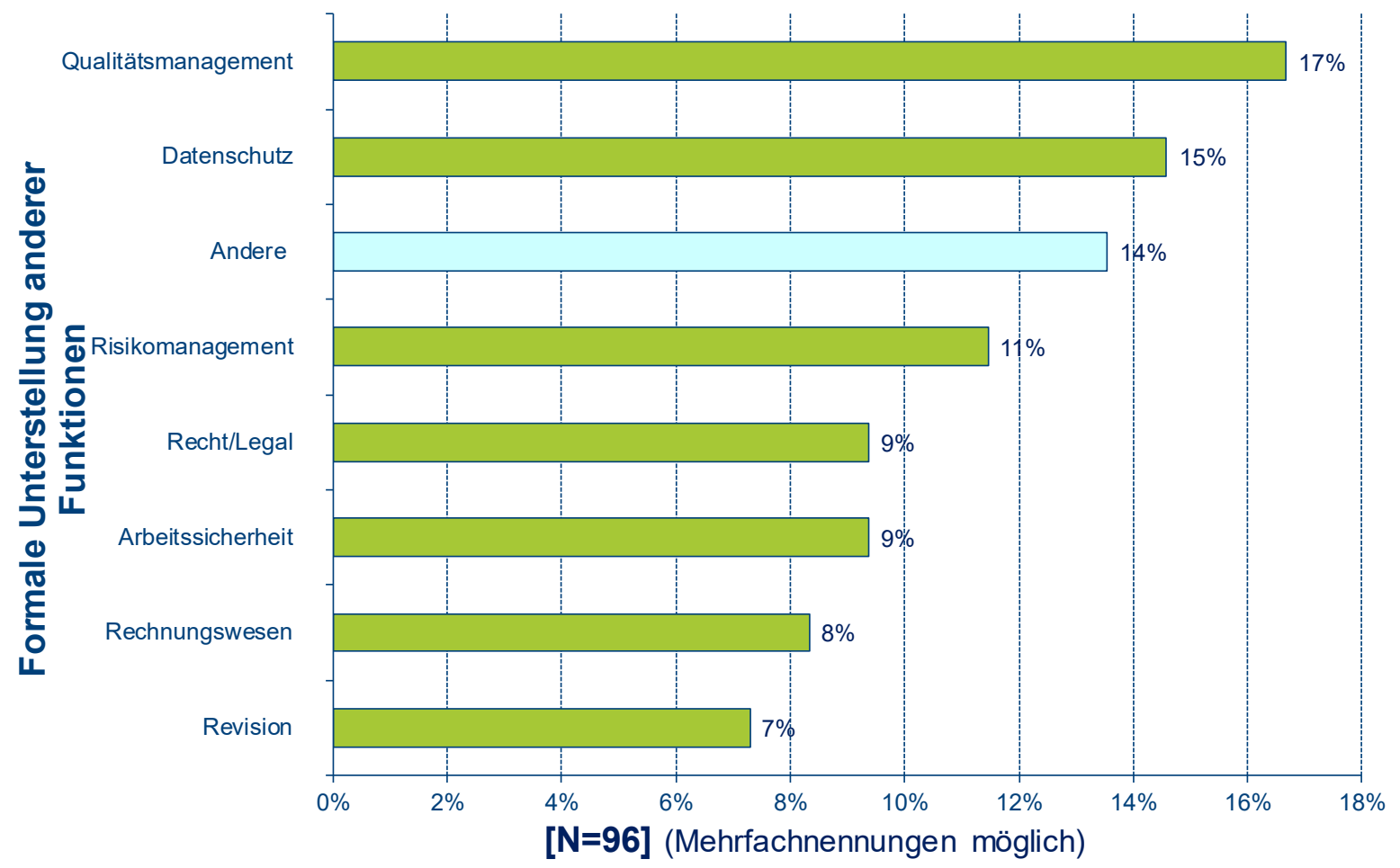

ABBiLdUng 16: Formale UnTERSTELLUNG ANDERER FUNKTIONEN

\footnotetext{
${ }^{6}$ Die Probanden geben an dieser Stelle individuelle Angaben anhand eines Freitextes an. Am häufigsten wird beispielsweise genannt, dass der Compliance-Organisation die IT-Sicherheit unterstellt ist oder keine Unterordnung anderer Einheiten im Unternehmen stattfindet.
} 


\subsection{Existenz von Compliance-Management im Unternehmen}

Diese Frage hatte das Ziel, herauszufinden, ob in den befragten Unternehmen ein Compliance-Management-System existiert.

37 Prozent der Befragten haben die Frage mit „Ja“ beantwortet und 58 Prozent mit „Nein“. Von diesen geben 15 Prozent an, ein Compliance-Management-System in Planung zu haben, während 48 Prozent dies nicht geplant haben.

\section{Existenz eines Compliance-Management-Systems}

[N=89]

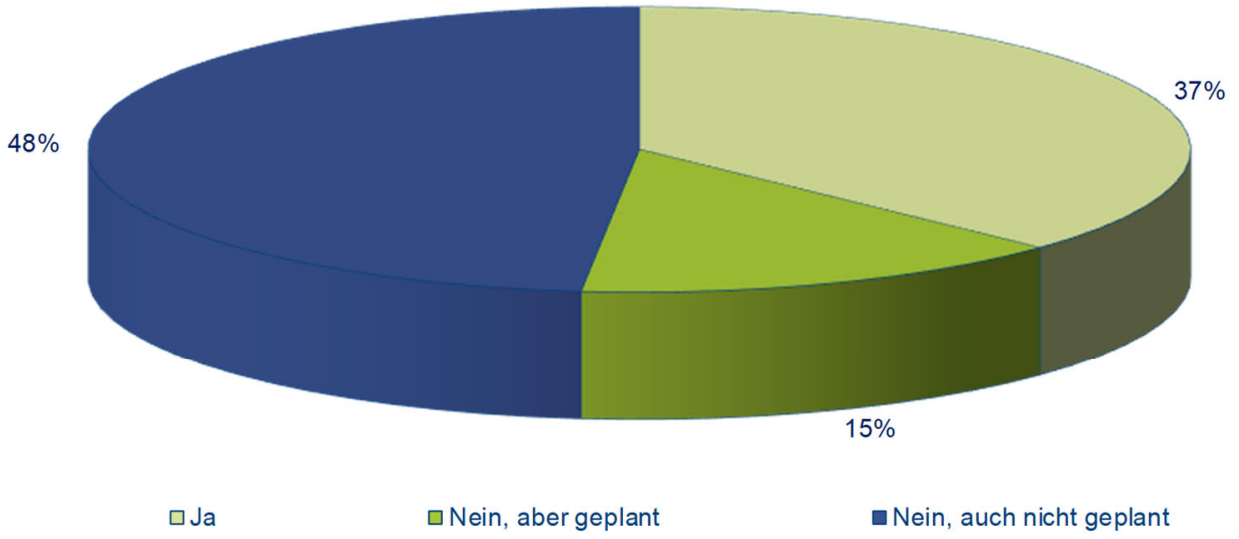




\subsection{Bedeutung von Compliance-Management}

Um die Bedeutung des Compliance-Managements in den befragten Unternehmen zu erfassen, wurden den Probanden fünf Antwortmöglichkeiten von den Ausprägungsstufen sehr niedrig bis sehr hoch gegeben.

Dabei haben 17 Prozent der Befragten angegeben, dass Compliance-Management für sie eine sehr niedrige bis niedrige Bedeutung hat. Für 31 Prozent ist die Bedeutung mittel und für 51 Prozent der Unternehmen wurde diese hoch bis sehr hoch eingeschätzt.

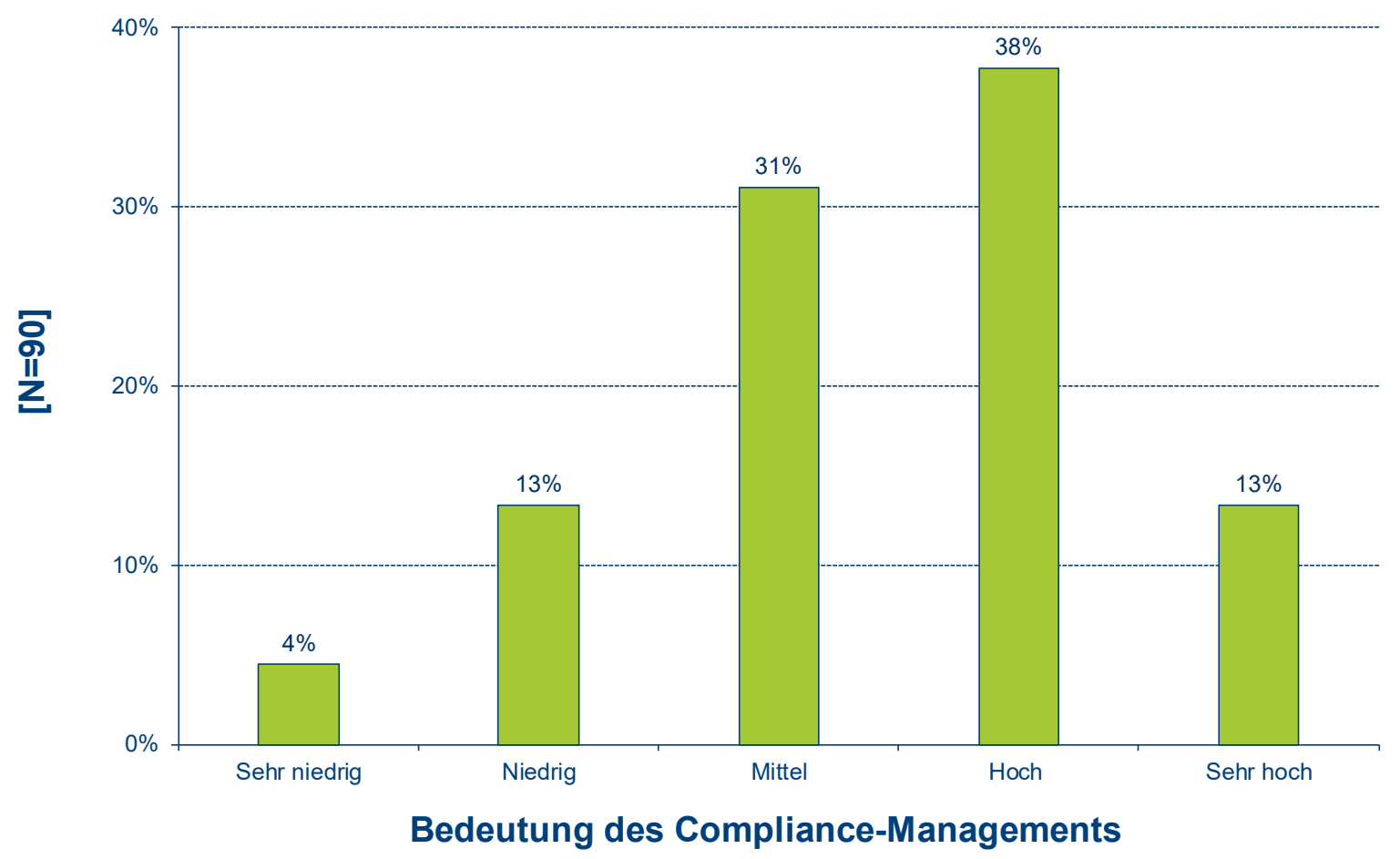

AbBildung 18: Bedeutung des Compliance-ManAgements 


\subsection{Funktionen des Compliance-Managements}

Hierbei wurde ermittelt, welche Funktionen das Compliance-Management und welchen Grad an Bedeutung diese für die befragten Unternehmen haben.

Für das Compliance-Management wurde die Funktion der Prävention von 72 Prozent $^{7}$ der Befragten als hoch bzw. sehr hoch bewertet. Als zweit bedeutendste Funktion für das Compliance-Management wird die Information über Regeln von 60 Prozent $^{8}$ der befragten Unternehmen als sehr hoch bzw. hoch eingeschätzt. Die Funktionen Kommunikation und Dokumentation werden von jeweils 54 Prozent $^{9}$ der Probanden als hoch bzw. sehr hoch bewertet. Für das Compliance-Management wird die Funktion der Korrektur nur von 40 Prozent der Probanden als hoch bzw. sehr hoch eingestuft, während die Funktion der Exkulpation von lediglich 30 Prozent als hoch bzw. sehr hoch bewertet wird. ${ }^{10}$

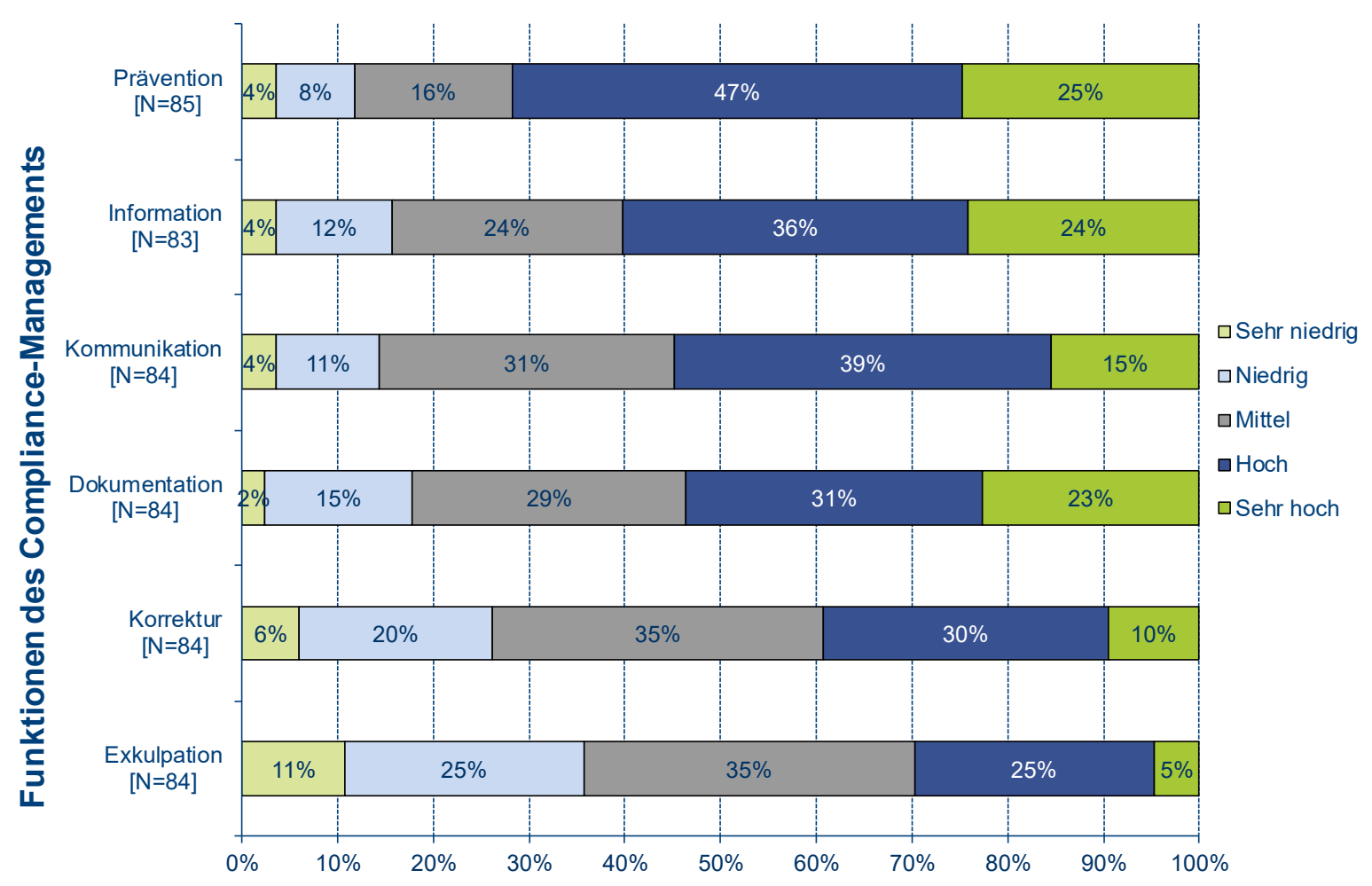

AbBildung 19: Funktionen des Compliance-MANAgements

\footnotetext{
${ }^{7}$ Grundgesamtheit der Nennungen: 85.

${ }^{8}$ Grundgesamtheit der Nennungen: 83.

${ }^{9}$ Jeweilige Grundgesamtheit der Nennungen: 84.

${ }^{10}$ Jeweilige Grundgesamtheit der Nennungen: 84.
} 


\subsection{Relevanz von Compliance-Management}

Um die Relevanz des Compliance-Managements in den einzelnen Unternehmensbereichen zu evaluieren, wurden die Probanden gebeten die Bedeutung des Compliance Managements für die jeweiligen Bereiche von sehr niedrig bis sehr hoch zu bewerten.

Für die Geschäftsführung bzw. den Vorstand wird die Relevanz des ComplianceManagements von 68 Prozent ${ }^{11}$ der befragten Unternehmen als sehr hoch bzw. hoch bewertet. Von 62 Prozent $^{12}$ der Probanden wird die Relevanz des ComplianceManagements im Bereich Rechnungswesen bzw. Controlling als sehr hoch bzw. hoch eingeschätzt. Für jeweils 60 Prozent der befragten Unternehmen ist die Bedeutung des Compliance-Managements im Unternehmensbereich Einkauf ${ }^{13}$ und Vertrieb ${ }^{14}$ sehr hoch bzw. hoch. Die Relevanz für den Bereich IT wird von 58 Prozent ${ }^{15}$ der Probanden als hoch bzw. sehr hoch bewertet. Eine hohe bzw. sehr hohe Relevanz des Compliance-Managements für den Aufsichtsrat bzw. Beirat messen lediglich 51 Prozent ${ }^{16}$ der befragten Unternehmen bei. Im Unternehmensbereich Personal liegen die Angaben zu einer hohen bzw. sehr hohen Relevanz bei 46 Prozent ${ }^{17}$.

\footnotetext{
${ }^{11}$ Grundgesamtheit der Nennungen: 87.

${ }^{12}$ Grundgesamtheit der Nennungen: 85.

${ }^{13}$ Grundgesamtheit der Nennungen: 85.

${ }^{14}$ Grundgesamtheit der Nennungen: 86.

${ }^{15}$ Grundgesamtheit der Nennungen: 83.

${ }^{16}$ Grundgesamtheit der Nennungen: 82.

${ }^{17}$ Grundgesamtheit der Nennungen: 86.
} 


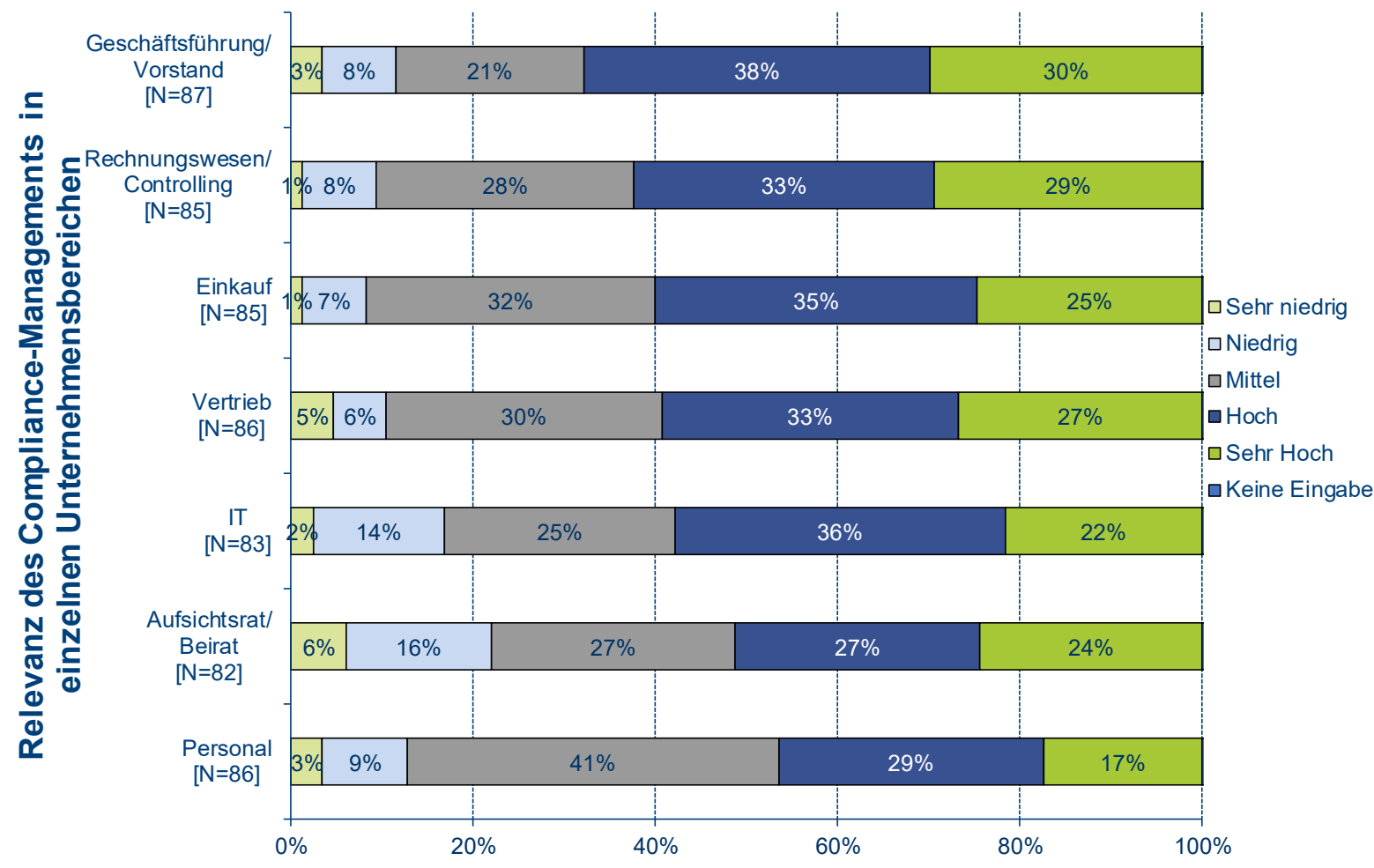

Abbildung 20: Relevanz des Compliance-Managements in einzelnen UNTERNEHMENSBEREICHEN 


\subsection{Aufgaben der Compliance-Organisation}

Diese Frage zielte darauf ab, herauszufinden, welche Aufgaben die ComplianceOrganisation im Unternehmen übernimmt.

65 Prozent der befragten Unternehmen geben an, dass dem ComplianceManagement Aufgaben, wie Richtlinien, Programme etc. im Unternehmen zugeordnet werden. Die Compliance-Kommunikation wird in 57 Prozent der Unternehmen von der Compliance-Organisation übernommen. Die Übernahme von Compliance-Kontrollen wird in 50 Prozent der Unternehmen der Compliance-Organisation überlassen, während die Compliance Organisation in 46 Prozent der befragten Unternehmen für die Compliance-Risikoanalyse verantwortlich ist. 41 Prozent der befragten Unternehmen übergeben die Aufgabe von Compliance-Schulungen an die Compliance-Organisation. Die Compliance-Organisation organisiert das Betreiben eines Hinweisgebersystems in 26 Prozent der befragten Unternehmen. Das Compliance Helpdesk wird in 17 Prozent der Unternehmen von der ComplianceOrganisation geführt. Die Ermittlung, Forensic und Detection ist in 17 Prozent der befragten Unternehmen der Compliance-Organisation untergeordnet. Sonstige Aufgaben werden in 6 Prozent der befragten Unternehmen übernommen und beinhalten beispielsweise das Durchführen von Zertifizierungen oder das Vorleben von Leitlinien. 


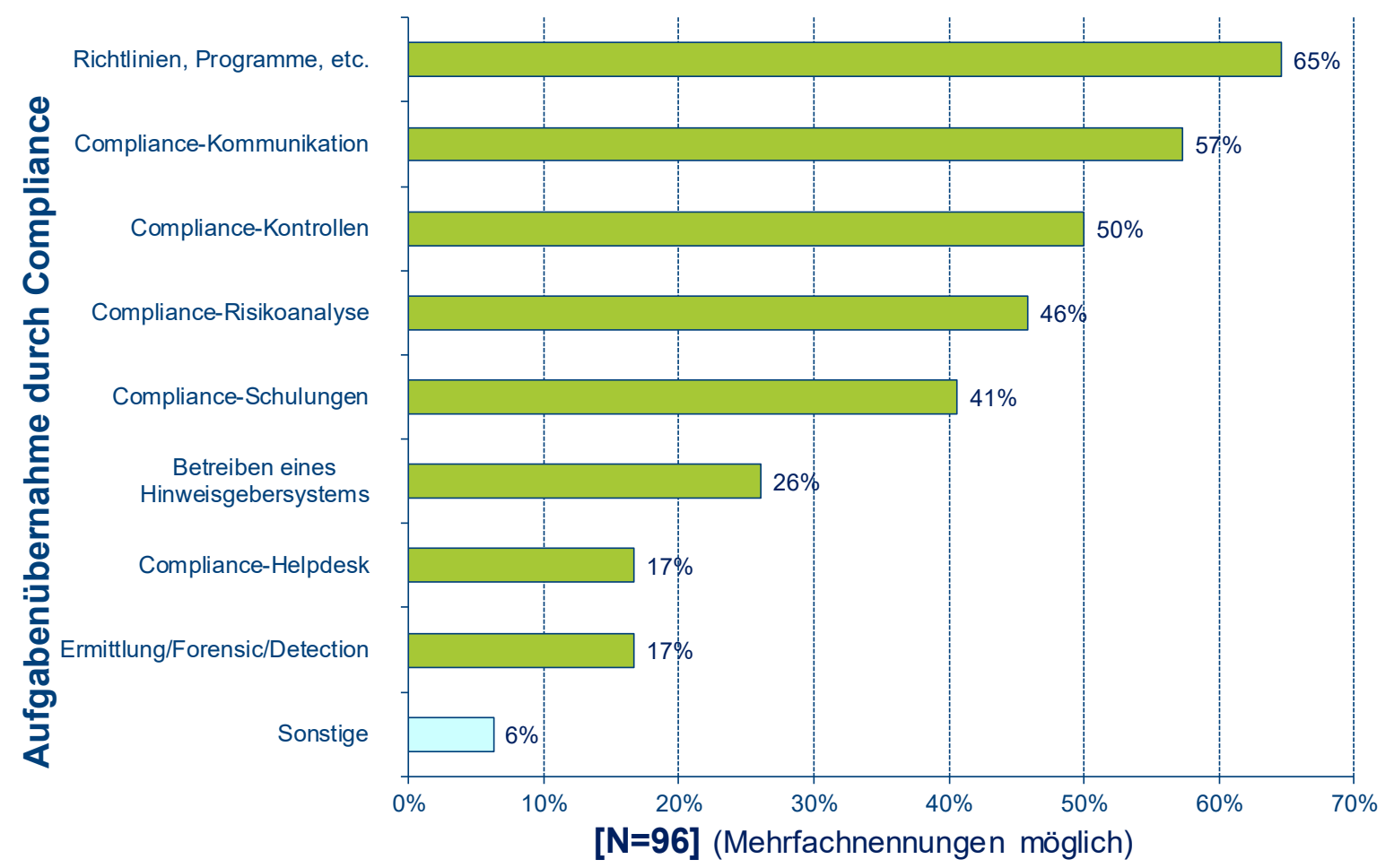

ABBILDUNG 21: AUfGABENÜBERNAHME DURCH COMPLIANCE 


\subsection{Instrumente zur Verankerung von Compliance}

Diese Frage zielte darauf ab, festzustellen, welche Instrumente zur Verankerung von Compliance in den befragten Unternehmen genutzt werden.

67 Prozent der befragten Unternehmen geben an, das Vorleben der Führungskräfte zur Verankerung der Compliance im Unternehmen zu nutzen. Weitere 64 Prozent der Befragten geben an, Richtlinien als Instrument zur Verankerung der Compliance im Unternehmen zu verwenden. Bei 63 Prozent der befragten Unternehmen wird Compliance im Unternehmensleitbild verankert, während die Compliance in 58 Prozent der befragten Unternehmen durch Einzelanweisungen festgeschrieben wird. Compliance wird bei 56 Prozent der Befragten im Verhaltenskodex festgehalten und bei 48 Prozent durch Kontrollen gewährleistet. Anhand von Dokumentationen wird Compliance bei 47 Prozent der Befragten verankert und bei 44 Prozent wird Compliance im Arbeitsvertrag festgehalten. Durch die Anwendung von Berichtwesen wird die Verankerung von Compliance in 29 Prozent der befragten Unternehmen sichergestellt und in 20 Prozent der befragten Unternehmen werden Workshops dazu angeboten. 20 Prozent der Unternehmen setzen auf den Einsatz einer ComplianceCheckliste und 16 Prozent auf eine Hinweisgeber-Hotline als Instrumente zur Implementierung der Compliance im Unternehmen. Im Gesellschaftsvertrag wird Compliance von 11 Prozent der befragten Unternehmen festgehalten. 2 Prozent der Unternehmen geben an, dass sonstige Instrumente zur Verankerung von Compliance verwendet werden. Diese sind das Anleiten über Lernvideos und das Durchführen von Schulungen über externe Organisationen. 


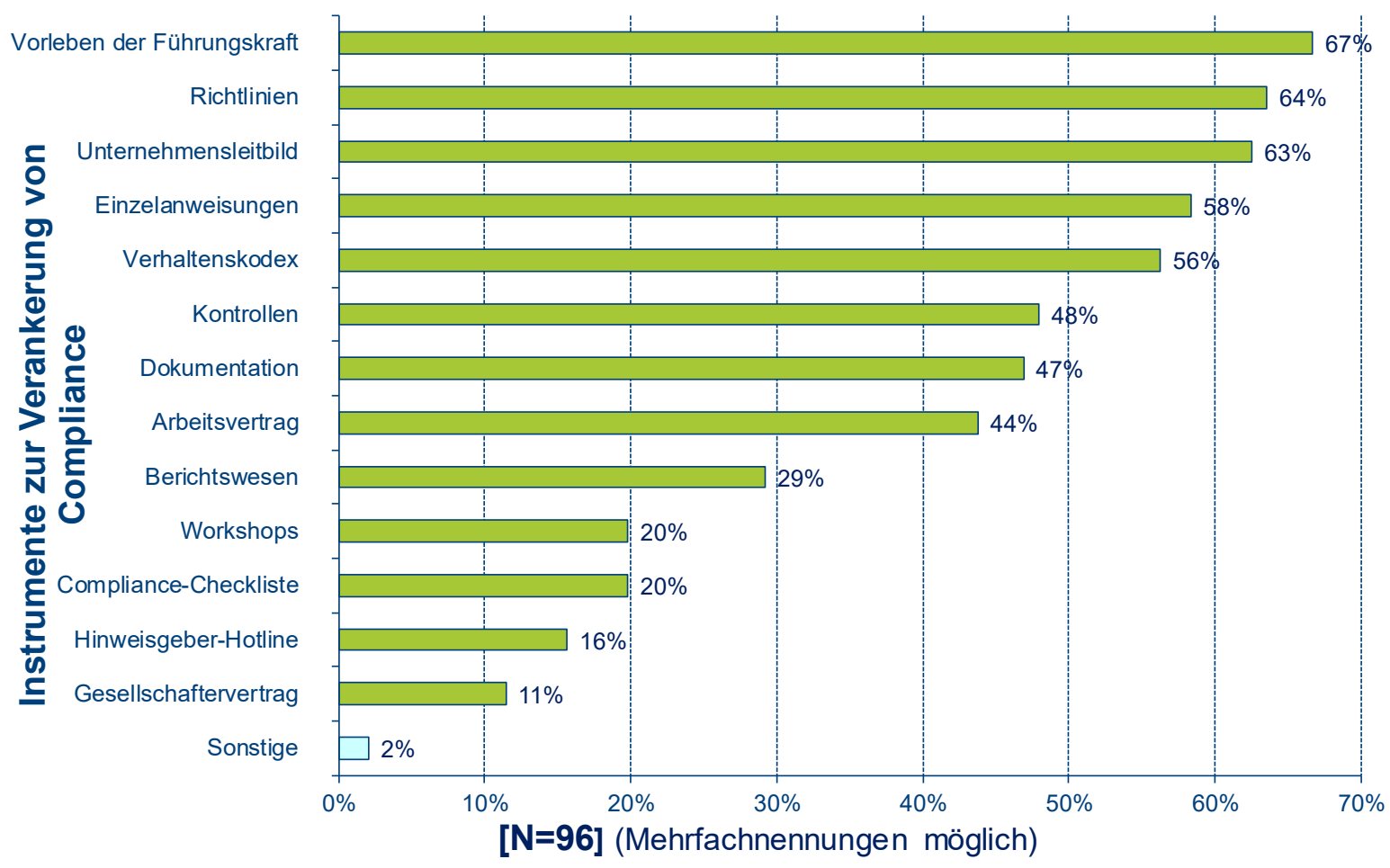

AbBildung 22: InStRumente ZUR VerAnkeRung Von Compliance 


\subsection{Rahmenwerk zur Entwicklung des Compliance-Managements}

Anhand dieser Frage wurde analysiert, ob das Compliance-Management des befragten Unternehmens anhand eines Rahmenwerks entwickelt wurde.

62 Prozent der befragten Unternehmen haben diese Frage mit „Nein“ beantwortet. 38 Prozent mit „Ja“, von welchen 27 Prozent ein selbstentwickeltes und 11 Prozent ein anerkanntes Rahmenwerk zur Entwicklung des Compliance-Managements verwenden.

\section{Rahmenwerk Compliance-Management}

$$
\text { [N=89] }
$$

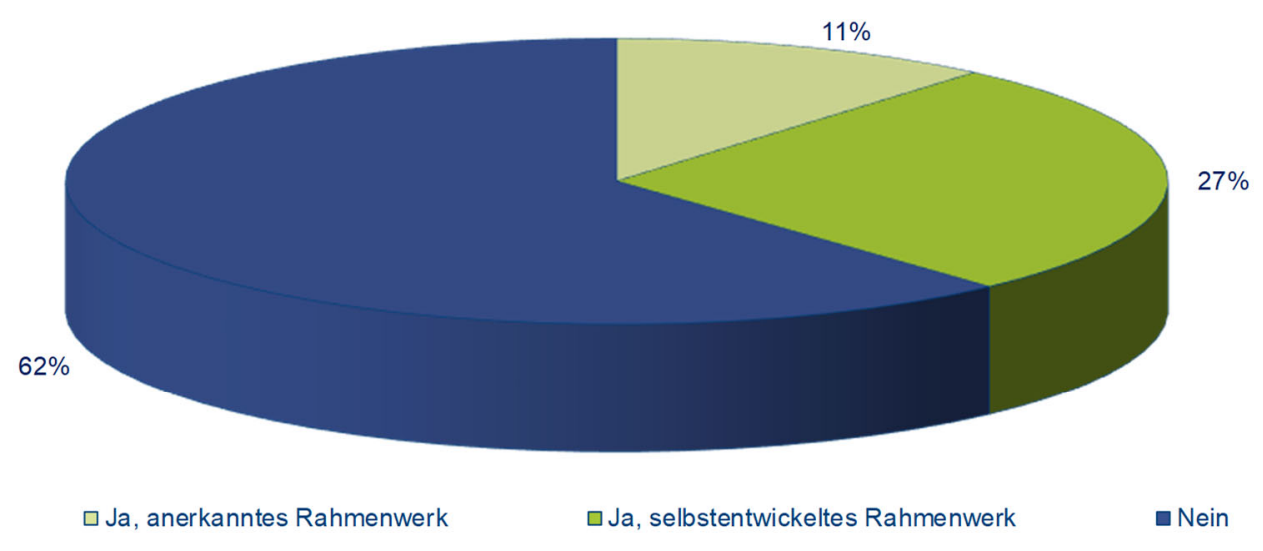




\subsection{Anerkannte Rahmenwerke}

Sofern in der vorangegangenen Frage angegeben wurde, dass ein anerkanntes Rahmenwerk verwendet wird, sollten die Probanden nun angeben, um welches Rahmenwerk es sich dabei handelt.

8 Prozent geben an, dass der Prüfstandard IDW PS 980 für das Compliance Management im Unternehmen verwendet wird. 6 Prozent der befragten Unternehmen setzen ISO 19600, den ISO-Standard für Compliance-Management-Systeme, und 2 Prozent den ISO 37001, den ISO-Standard für Antikorruptionsmanagementsysteme, ein. Den TÜV Rheinland TR CMS 101:2015, der Standard für ComplianceManagement-Systeme, wird von 2 Prozent der befragten Unternehmen verwendet, während der ISO 26000, ein ISO-Standard für Corporate Social Responsibility, lediglich von 1 Prozent der Befragten angewandt wird. Die zur Ausgestaltung und Beurteilung von Compliance-Management-Systemen verwendete KICG CMS-Leitlinie und der Hamburger Compliance Standard werden von keinem der befragten Unternehmen angewendet.

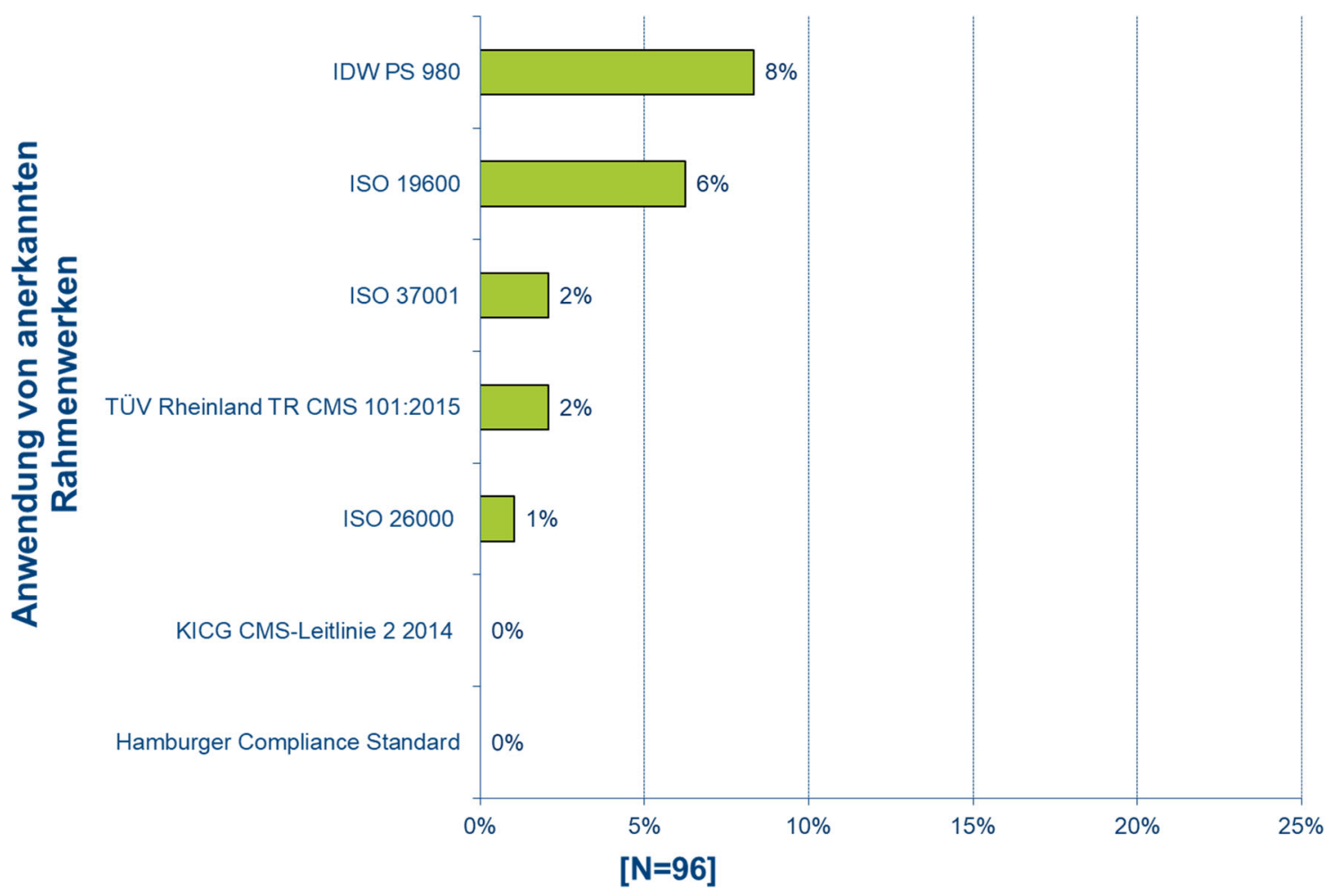




\subsection{Zufriedenheit von Aspekten im Vergleich zum stärksten Wettbewerber}

Die Frage zielte darauf $a b$, die Zufriedenheit der befragten Unternehmen mit angegebenen Aspekten im Vergleich zum stärksten Wettbewerber abzufragen.

Im Vergleich zu ihrem stärksten Wettbewerber sind 82 Prozent $^{18}$ der Befragten mit der Entwicklung ihres Unternehmens zufrieden bzw. sehr zufrieden. Jeweils 75 Prozent der Probanden sind mit dem Produkterfolg ${ }^{19}$ und dem Grad der Kundenloyalität ${ }^{20}$ im Vergleich zum stärksten Wettbewerber zufrieden bzw. sehr zufrieden. 67 Prozent $^{21}$ der befragten Unternehmen sind mit der Wachstumsrate im Vergleich zu ihrem stärksten Wettbewerber zufrieden bzw. sehr zufrieden, während diese Zufriedenheit 63 Prozent ${ }^{22}$ der Probanden in Bezug auf die akquirierten Neukunden angeben. Mit dem Marktanteil sind im Vergleich zum stärksten Wettbewerber 62 Prozent ${ }^{23}$ und mit der Gewinnprognose 56 Prozent $^{24}$ zufrieden bzw. sehr zufrieden. 57 Prozent der Probanden empfinden ihre Profitabilität im Vergleich zum stärksten Wettbewerber als zufrieden bzw. sehr zufrieden stellend, während lediglich 45 Prozent der Befragten ihre Marketingaktivitäten als zufrieden bzw. sehr zufrieden stellend empfinden. ${ }^{25}$

\footnotetext{
${ }^{18}$ Grundgesamtheit der Nennungen: 83.

${ }^{19}$ Grundgesamtheit der Nennungen: 80 .

${ }^{20}$ Grundgesamtheit der Nennungen: 81.

${ }^{21}$ Grundgesamtheit der Nennungen: 83.

22 Grundgesamtheit der Nennungen: 81.

${ }^{23}$ Grundgesamtheit der Nennungen: 80.

${ }^{24}$ Grundgesamtheit der Nennungen: 82.

25 Jeweilige Grundgesamtheit der Nennungen: 80.
} 


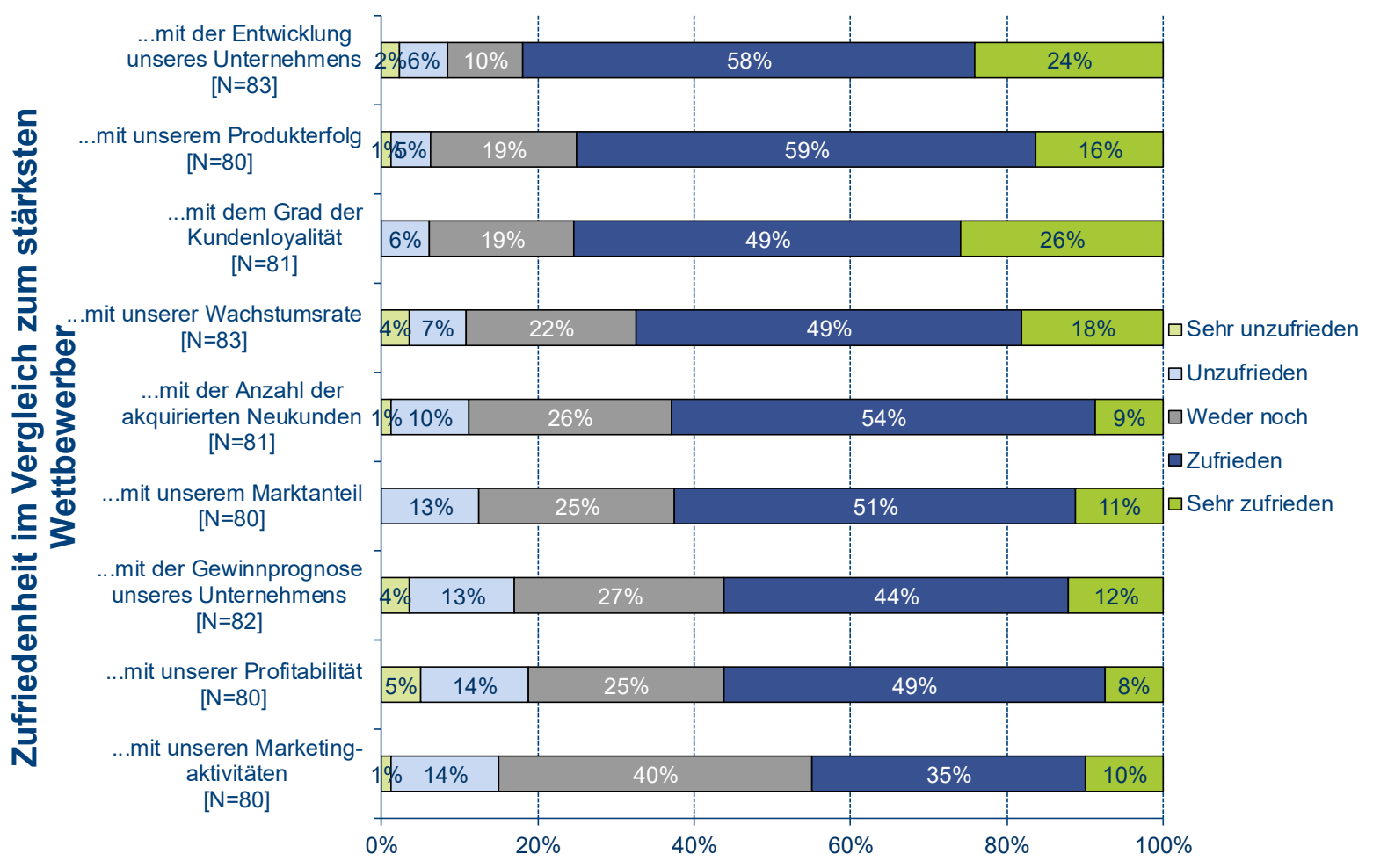

ABbiLdung 25: ZUfRIEDENHEIT IM VeRgleich ZUM STÄRKSTEN WetTBEWERBER 


\subsection{Zufriedenheit mit dem Compliance-Management im Unternehmen}

Hierbei sollten die befragten Probanden ihre Zufriedenheit mit dem ComplianceManagement im Unternehmen bewerten.

1 Prozent der befragten Unternehmen bewerten die Zufriedenheit mit dem eigenen Compliance-Management mit sehr unzufrieden, während 10 Prozent der Probanden angeben unzufrieden zu sein. Mit mittlerer Zufriedenheit wurde das ComplianceManagement von 45 Prozent der Befragten bewertet. 38 Prozent der befragten Unternehmen sind zufrieden und 5 Prozent sind sogar sehr zufrieden.

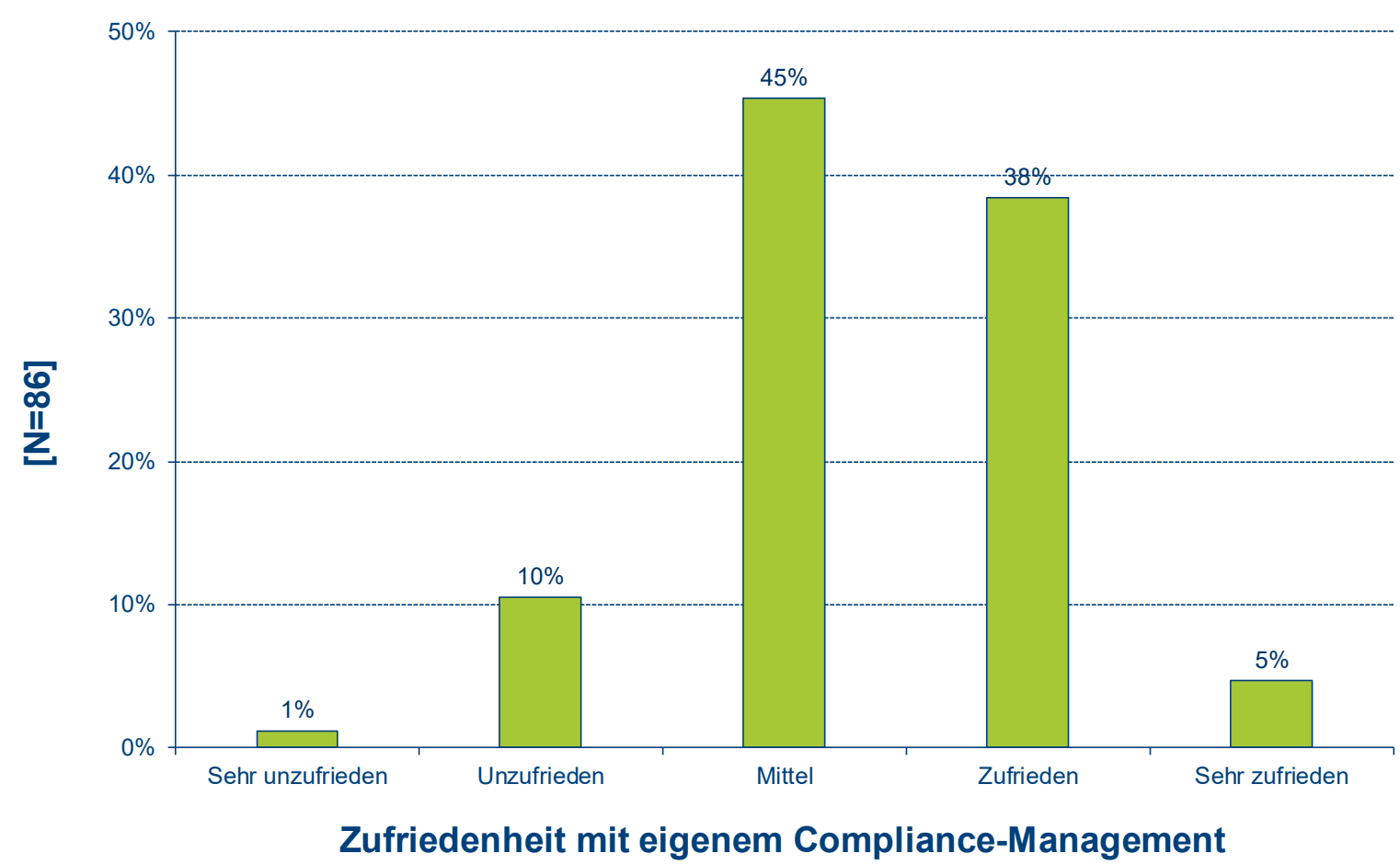




\subsection{Assoziation von Aufwandsaspekten mit Compliance- Management}

Anhand dieser Frage wurde analysiert, welche Aufwandsaspekte die Befragten mit dem Compliance-Management assoziieren.

76 Prozent der befragten Unternehmen geben an, dass sie Verwaltungsaufwendungen als Aufwandsaspekt mit Compliance-Management in Verbindung bringen, während 60 Prozent angeben, Beratungs- und Schulungsaufwendungen als Aufwandsaspekt mit Compliance-Management zu assoziieren. Personalaufwendungen assoziieren 53 Prozent und prozessabhängige Aufwendungen werden von 47 Prozent der befragten Unternehmen als Aufwandsaspekt des Compliance-Managements angesehen. ITAufwendungen werden von 35 Prozent der Probanden als Aufwandsaspekt betrachtet.

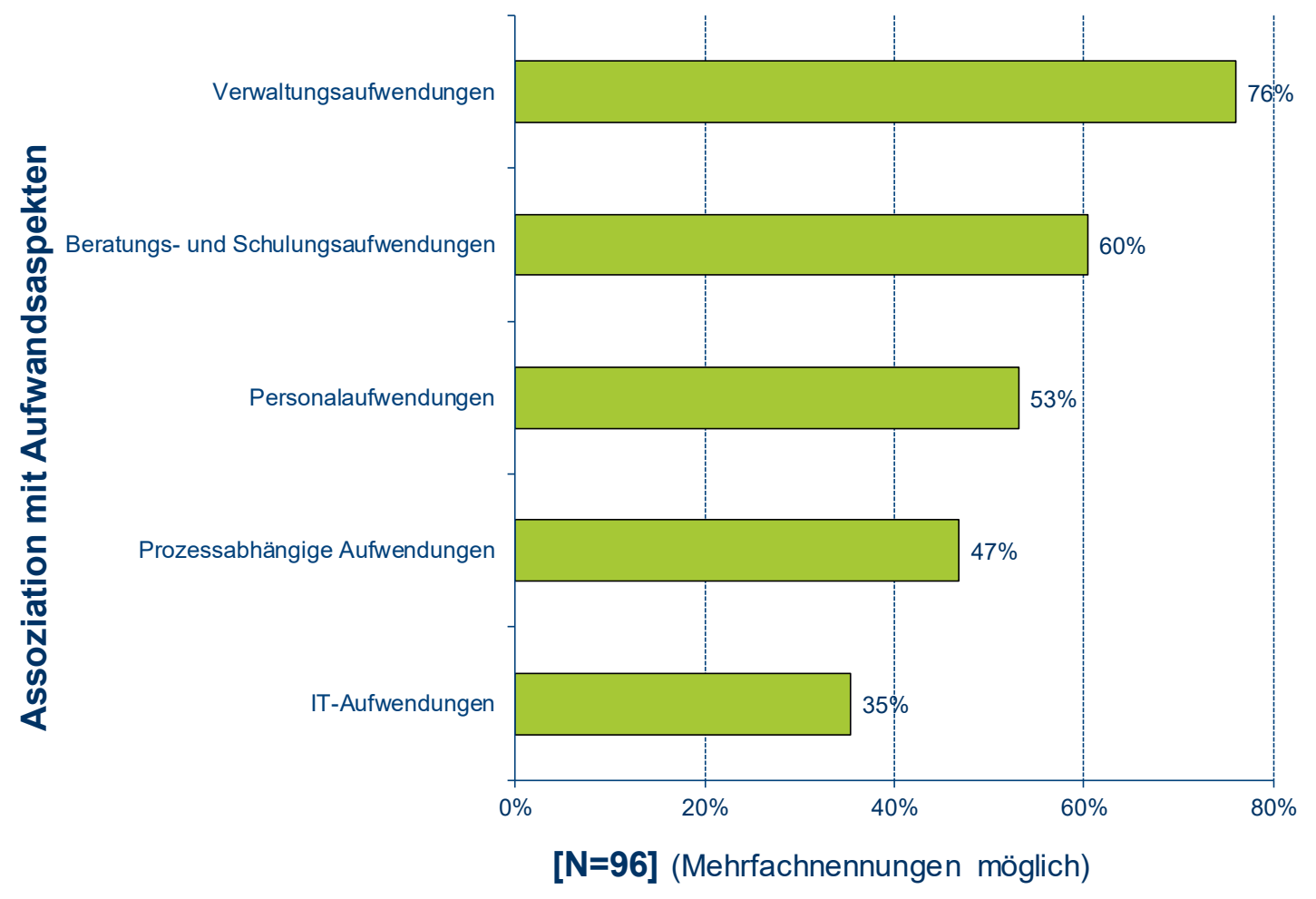




\subsection{Assoziation von Nutzenaspekte mit Compliance-Management}

Diese Frage diente dazu, herauszufinden, welche Nutzenaspekte die befragten Probanden durch das Compliance-Management wahrnehmen.

Der Schutz vor Haftung wird von 70 Prozent und die Erhöhung der Handlungssicherheit von 64 der Probanden als Nutzungsaspekte des ComplianceManagements assoziiert. Als weiteren Nutzenaspekt von Compliance-Management sehen 55 Prozent die Verbesserung der Reputation bzw. Werteorientierung und 39 Prozent ein gesteigertes Geschäfts- und Prozessverständnis. 25 Prozent verbinden die Steigerung der Effizienz als Nutzenaspekt mit dem Compliance-Management. Nur 17 Prozent der befragten Unternehmen assoziieren die Verbesserung der Wettbewerbsposition des Unternehmens als Nutzungsaspekts des ComplianceManagements.

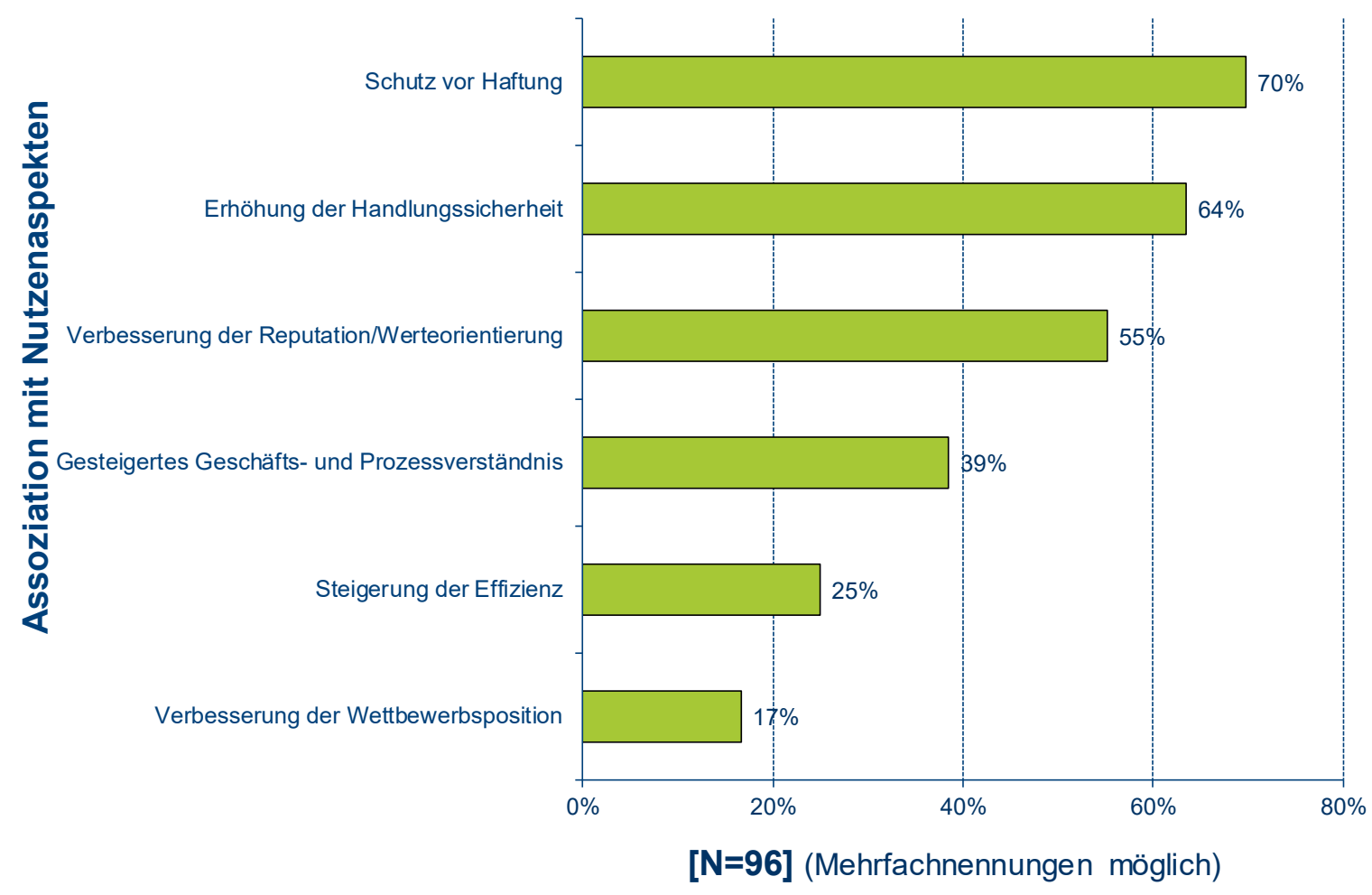




\subsection{Risiko für unlautere Handlungen im Unternehmen}

Diese Frage zielte drauf ab, herauszufinden, wie hoch die Probanden das Risiko für unlautere Handlungen in ihrem Unternehmen einschätzen.

71 Prozent der Probanden schätzen das Gefahrenpotenzial von unlauteren Handlungen im Unternehmen als niedrig bis sehr niedrig ein. Ein mittleres Risiko sehen 22 Prozent der Befragten, während und 7 Prozent eine hohe Gefahr und 1 Prozent eine sehr hohe Gefahr von unlauteren Handlungen im Unternehmen sehen.

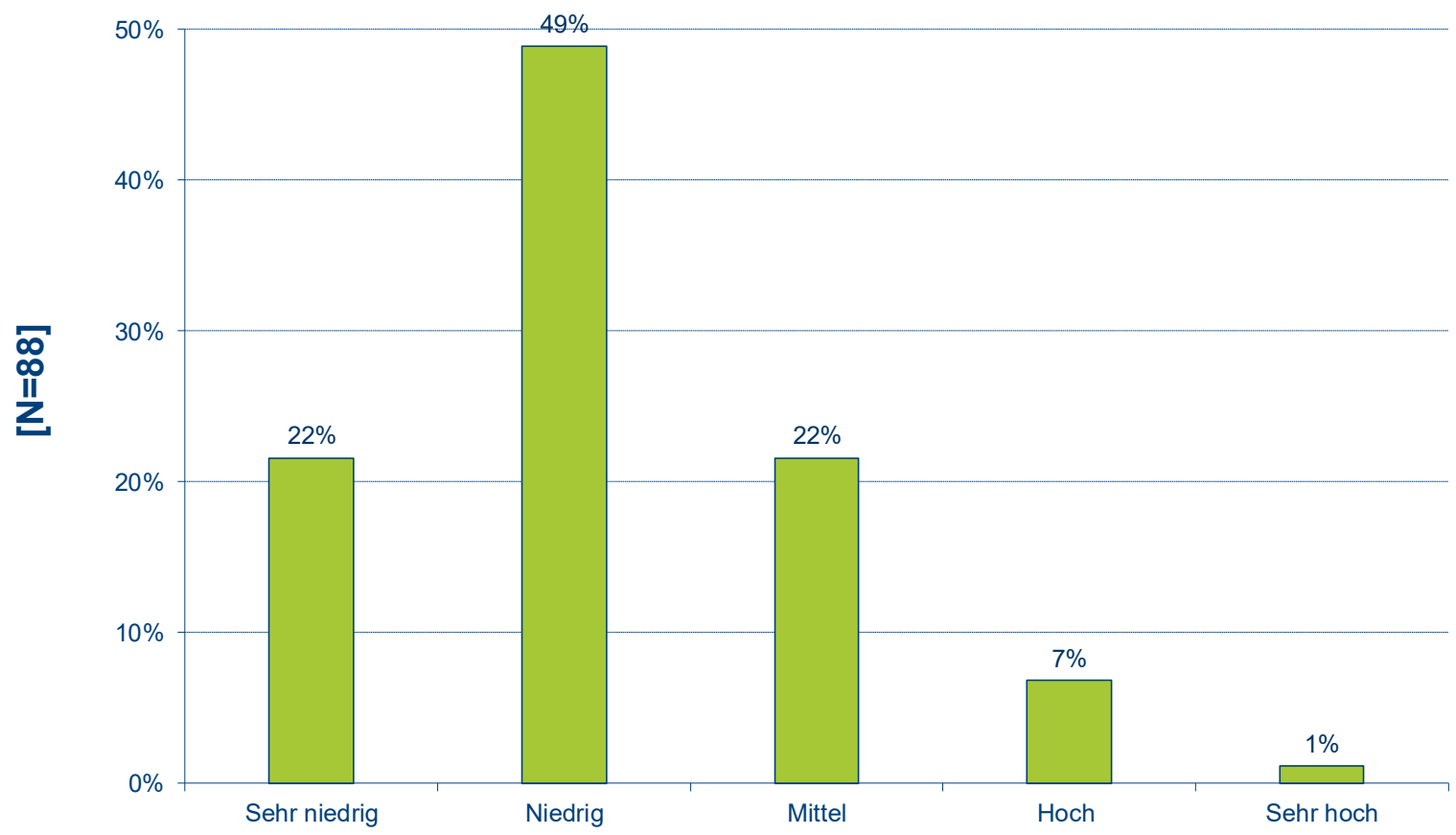

Einschätzung der Gefahr von unlauteren Handlungen 


\subsection{Einfluss von Compliance-Risiken auf das Unternehmen}

In dieser Frage sollten die befragten Unternehmen evaluieren, welche ComplianceRisiken ihrer Ansicht nach einem erhöhten Einfluss auf das Unternehmen haben.

Die Mehrheit der befragten Unternehmen, 59 Prozent ${ }^{26}$, messen der Datensicherheit als Risiko einen starken bzw. sehr starken Einfluss auf das Unternehmen bei. Als weitere Risiken mit einem starken bzw. sehr starken Einfluss auf das Unternehmen werden Cyber-Attacken mit 49 Prozent $^{27}$ und der Datenschutz mit 48 Prozent $^{28}$ genannt. In dem Risiko des Geschäftspartner-Risikomanagements sehen 27 Prozent $^{29}$ und in dem Risiko der Geschäftspartner-Due Diligence sehen lediglich 25 Prozent ${ }^{30}$ der Befragten einen starken bzw. sehr starken Einfluss auf das Unternehmen. Als weniger relevant werden die Risiken durch Social Media betrachtet, welche von nur 14 Prozent ${ }^{31}$ der Probanden als starker bzw. sehr starker Einfluss auf das Unternehmen eingeschätzt wird. Das Risiko Bestechung und Bestechlichkeit wird von jeweils 11 Prozent der Befragten als starken bzw. sehr starken Einfluss auf das Unternehmen eingeschätzt. ${ }^{32}$ Als noch weniger relevant werden lediglich das Risiko Financial Crime bzw. Geldwäsche, die Risiken im Umgang mit künstlicher Intelligenz und die Risiken durch neue (digitale) Währungen mit jeweils 8 Prozent $^{33}, 5$ Prozent $^{34}$ und 2 Prozent $^{35}$ starkem bzw. sehr starkem Einfluss auf das Unternehmen, angesehen.

\footnotetext{
${ }^{26}$ Grundgesamtheit der Nennungen: 88 .

${ }^{27}$ Grundgesamtheit der Nennungen: 86.

${ }^{28}$ Grundgesamtheit der Nennungen: 87.

${ }^{29}$ Grundgesamtheit der Nennungen: 86.

${ }^{30}$ Grundgesamtheit der Nennungen: 87.

${ }^{31}$ Grundgesamtheit der Nennungen: 87.

32 Jeweilige Grundgesamtheit der Nennungen: 85 .

${ }^{33}$ Grundgesamtheit der Nennungen: 86.

${ }^{34}$ Grundgesamtheit der Nennungen: 85.

${ }^{35}$ Grundgesamtheit der Nennungen: 84.
} 

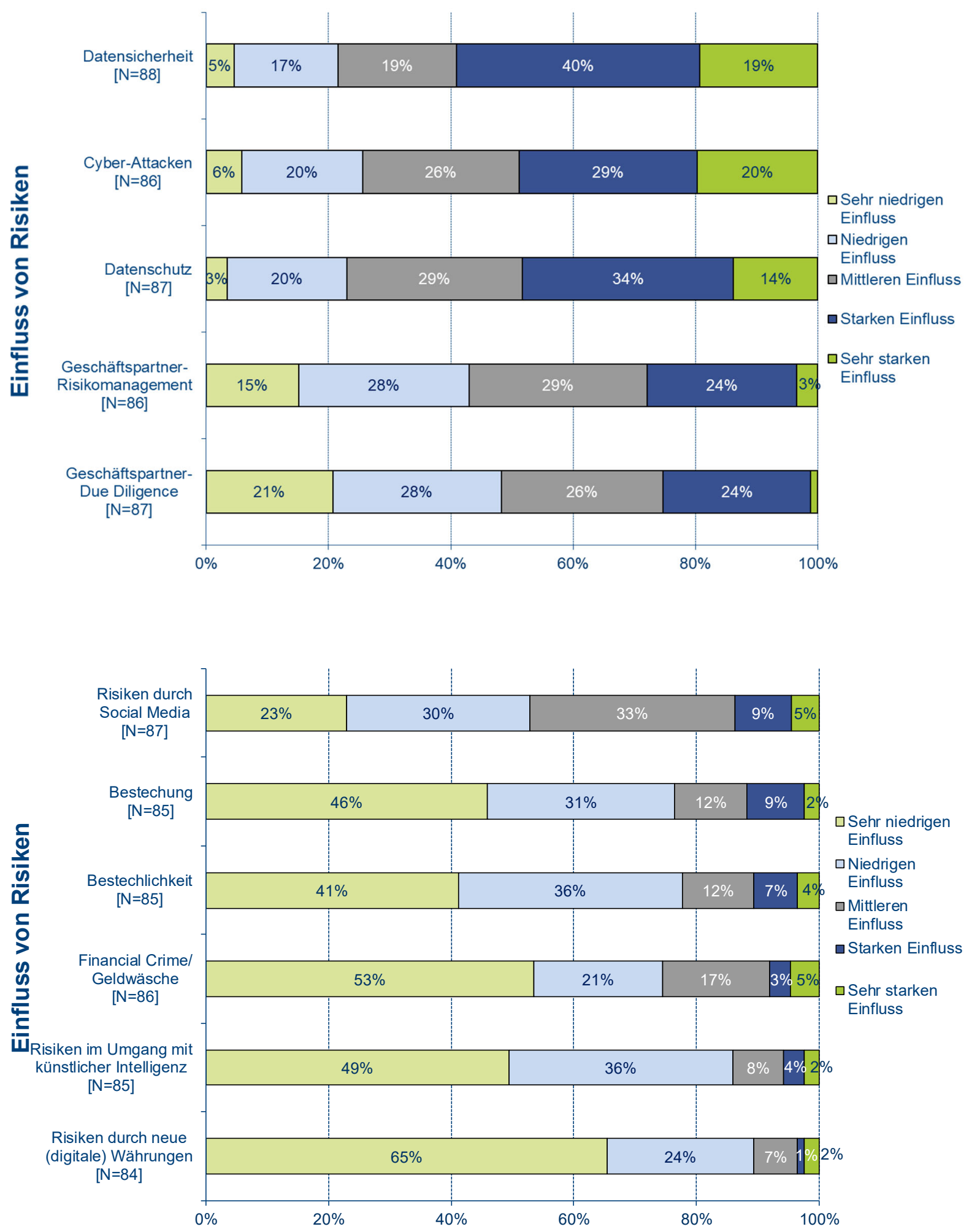

ABBILdUNG 30: EINFLUSS VON RISIKEN 


\section{Demografische Daten}

Kapitel 4 enthält Angaben wie beispielsweise zum Bildungsabschluss, Alter oder Geschlecht, die Rückschlüsse auf die Hintergründe der Befragten zulasse sollen.

\subsection{Höchster Bildungsabschluss}

83 Prozent und somit die Mehrheit der Probanden geben an ein Studium absolviert zu haben. 10 Prozent der Probanden haben Abitur und 5 Prozent einen Haupt- bzw. Realschulabschluss. 2 Prozent der befragten Probanden haben promoviert.

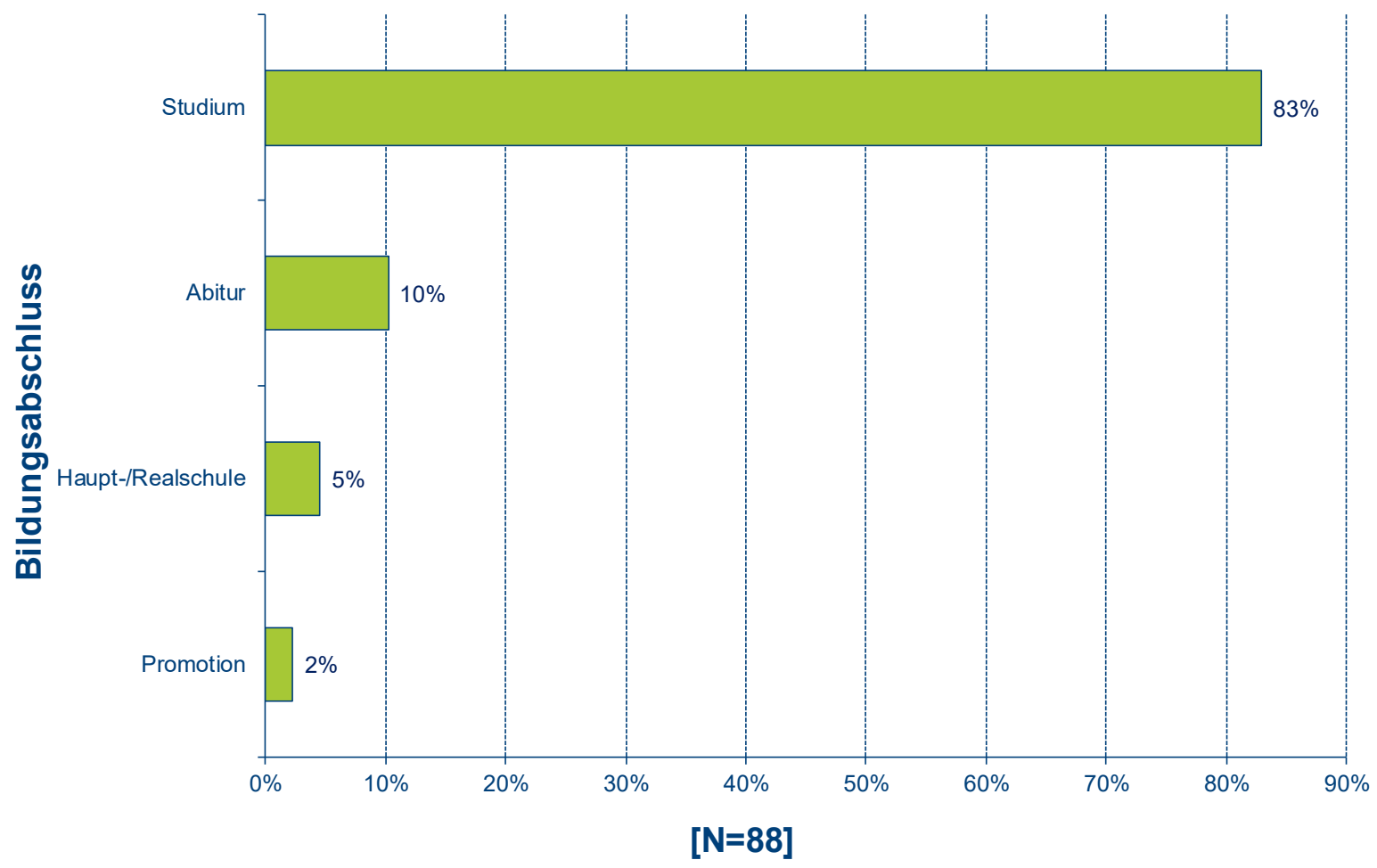




\subsection{Ausrichtung Studium oder Ausbildung}

Die Befragten sollten hier die Fachrichtung ihres Studiums oder ihrer Ausbildung aus den zur Auswahl stehenden Elementen auswählen.

Etwas mehr als die Hälfte der Probanden, 53 Prozent, haben ein wirtschaftswissenschaftliches Studium bzw. eine kaufmännische Ausbildung abgelegt. 28 Prozent geben an ein technisches oder naturwissenschaftliches Studium bzw. Ausbildung absolviert zu haben und 15 Prozent haben ein rechtswissenschaftliches Studium bzw. Ausbildung abgelegt. Ein Studium in einem anderen Bereich der Geistes- bzw. Sozialwissenschaften oder eine pädagogische Ausbildung haben 8 Prozent und 6 Prozent haben ein sonstiges Studium bzw. eine sonstige Ausbildung absolviert. Jeweils 1 Prozent der Befragten gibt an, entweder ein Studium der Kommunikations- oder Medienwissenschaft, Publizistik und Journalistik oder weder ein Studium noch eine Ausbildung beendet zu haben.

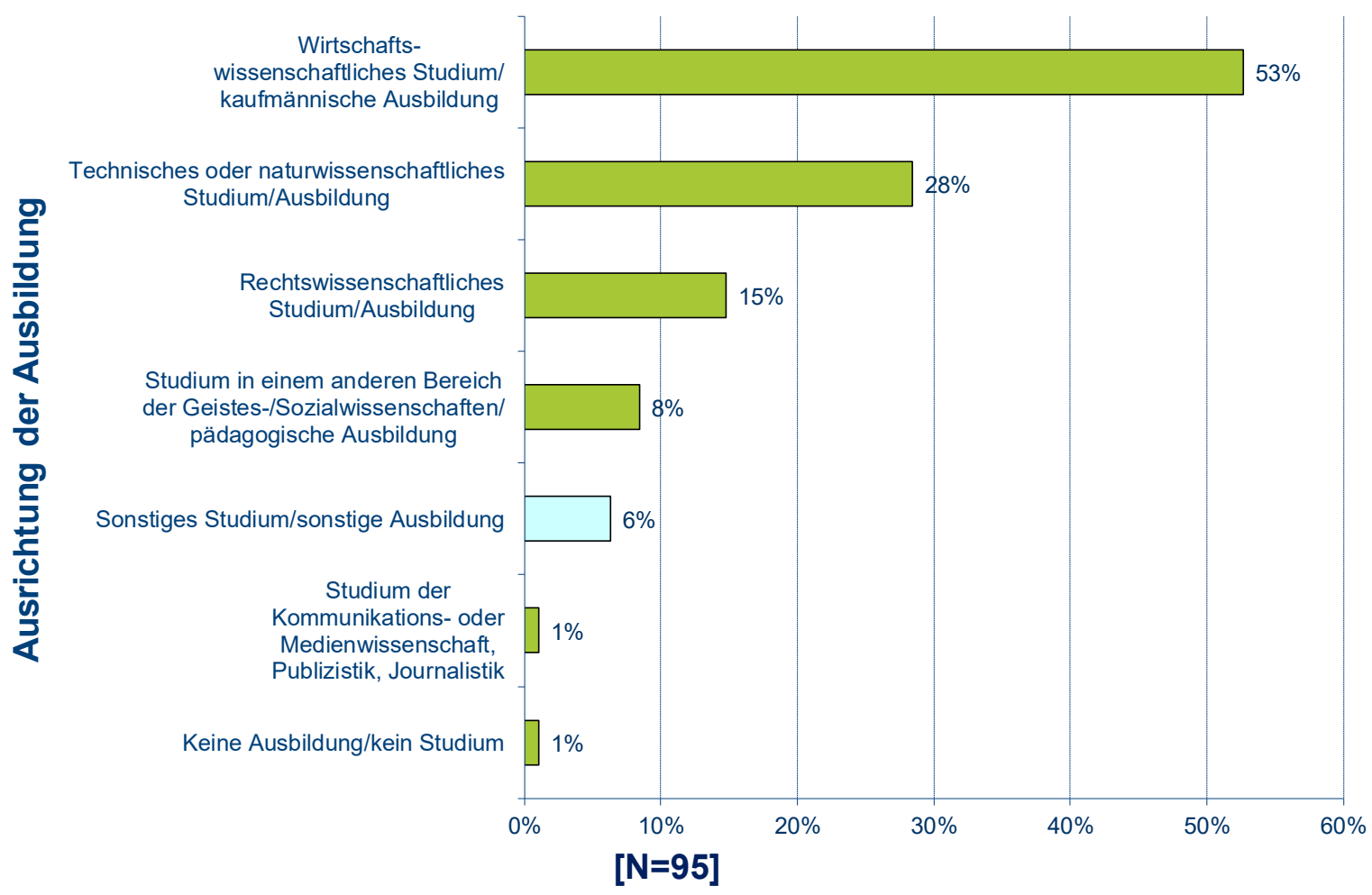




\subsection{Betrachtete Perspektive auf Compliance}

Die Probanden wurden hierbei gefragt, ob sie Compliance aus einer betriebswirtschaftlichen oder aus einer rechtlichen Perspektive heraus einschätzen.

55 Prozent der Befragten geben an, dass sie Compliance aus einer rechtlichen Perspektive heraus bewerten. 45 Prozent betrachten Compliance aus einer betriebswirtschaftlichen Perspektive.

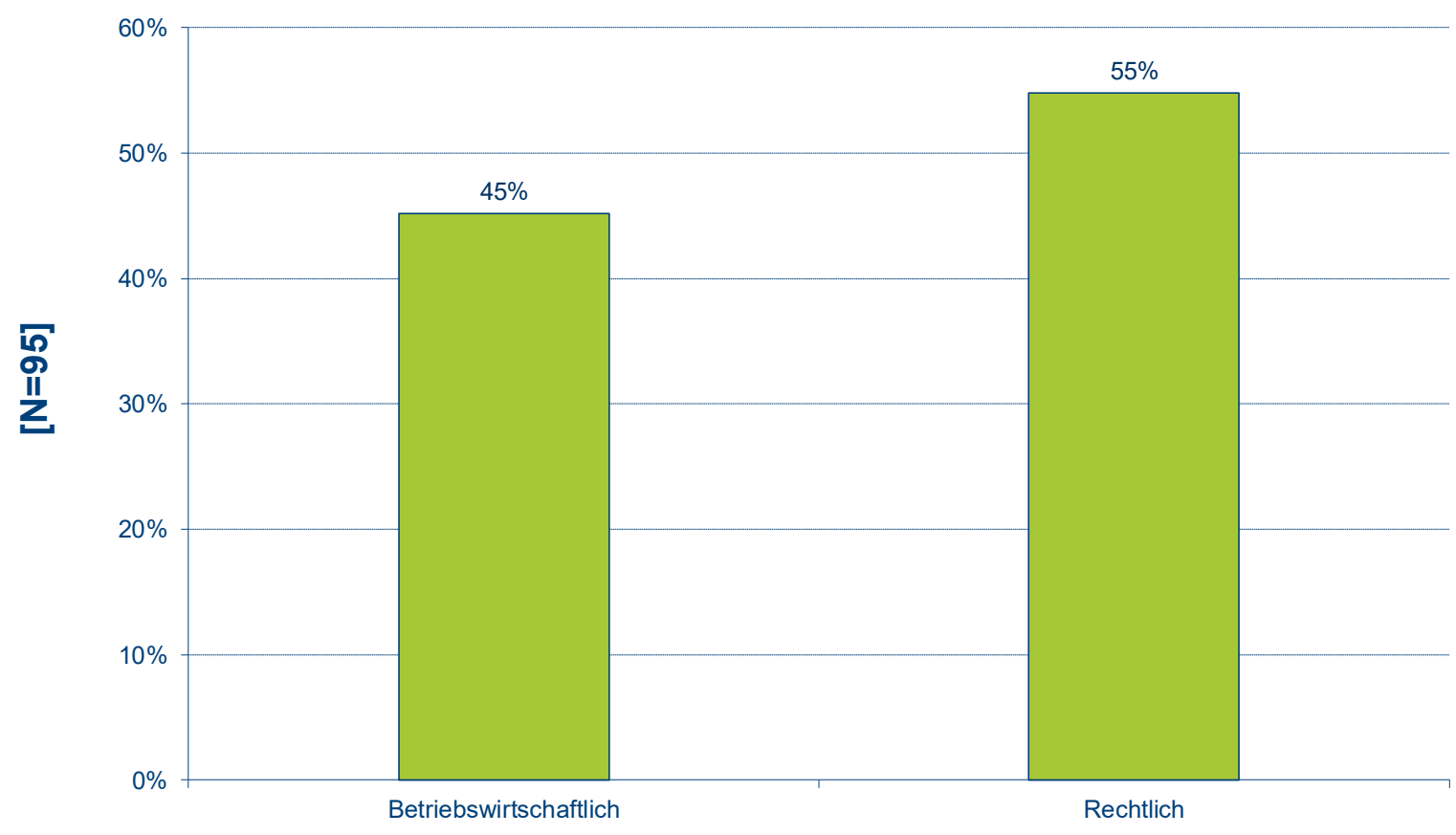

Betrachtungsperspektive von Compliance 


\subsection{Stellenbezeichnung}

Die befragten Probanden wurden außerdem gebeten ihre jeweilige Position im Unternehmen anzugeben.

36 Prozent geben Sonstige bei den zur Auswahl stehenden Positionen an. 34 Prozent geben an, in der Geschäftsführung oder im Vorstand tätig zu sein, 13 Prozent sind als Chief Compliance Officer und 8 Prozent als Chief Financial Officer angestellt. Als Mitarbeiter im CFO-Bereich sind 7 Prozent tätig und 2 Prozent der Befragten sind Mitarbeiter der Rechtsabteilung. Im Beirat bzw. Aufsichtsrat, sowie als Mitarbeiter im CCO-Bereich ist keiner der befragten Probanden tätig.

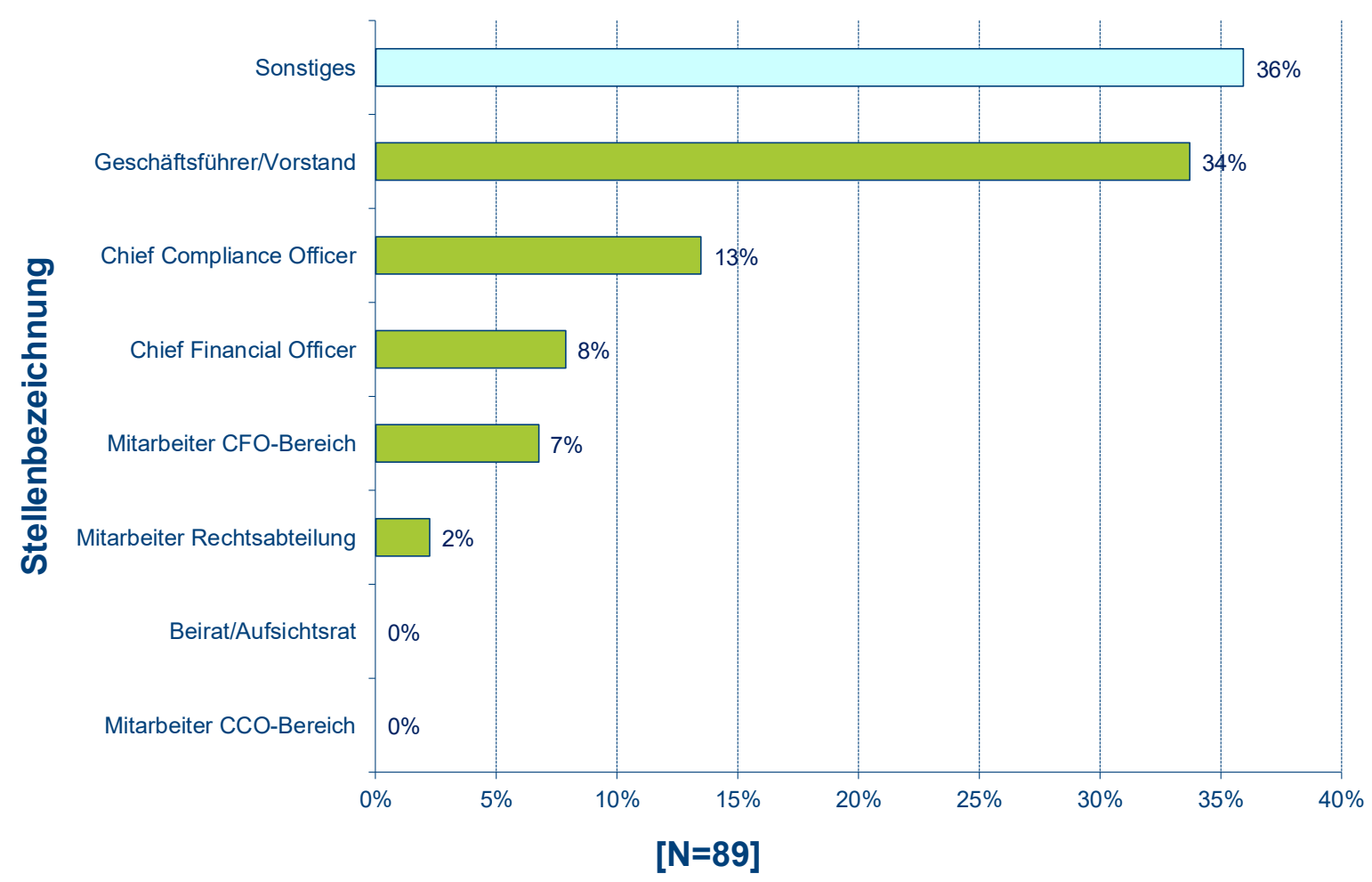




\subsection{Alter}

Diese Frage diente dazu, die befragten Probanden in verschiedene Altersklassen zu kategorisieren.

1 Prozent der Befragten ist jünger als 21 Jahre alt. 3 Prozent der Antwortenden sind zwischen 21 und 27 Jahren und 11 Prozent zwischen 28 und 35 Jahren. 19 Prozent sind in einem Alter zwischen 36 und 45 Jahren. Die Mehrzahl der Befragten, 34 Prozent, geben an, zwischen 46 bis 55 Jahre alt zu sein. Ein Alter zwischen 56 bis 65 Jahren haben 31 Prozent der Befragten. Über 66 Jahre ist keiner der Probanden.

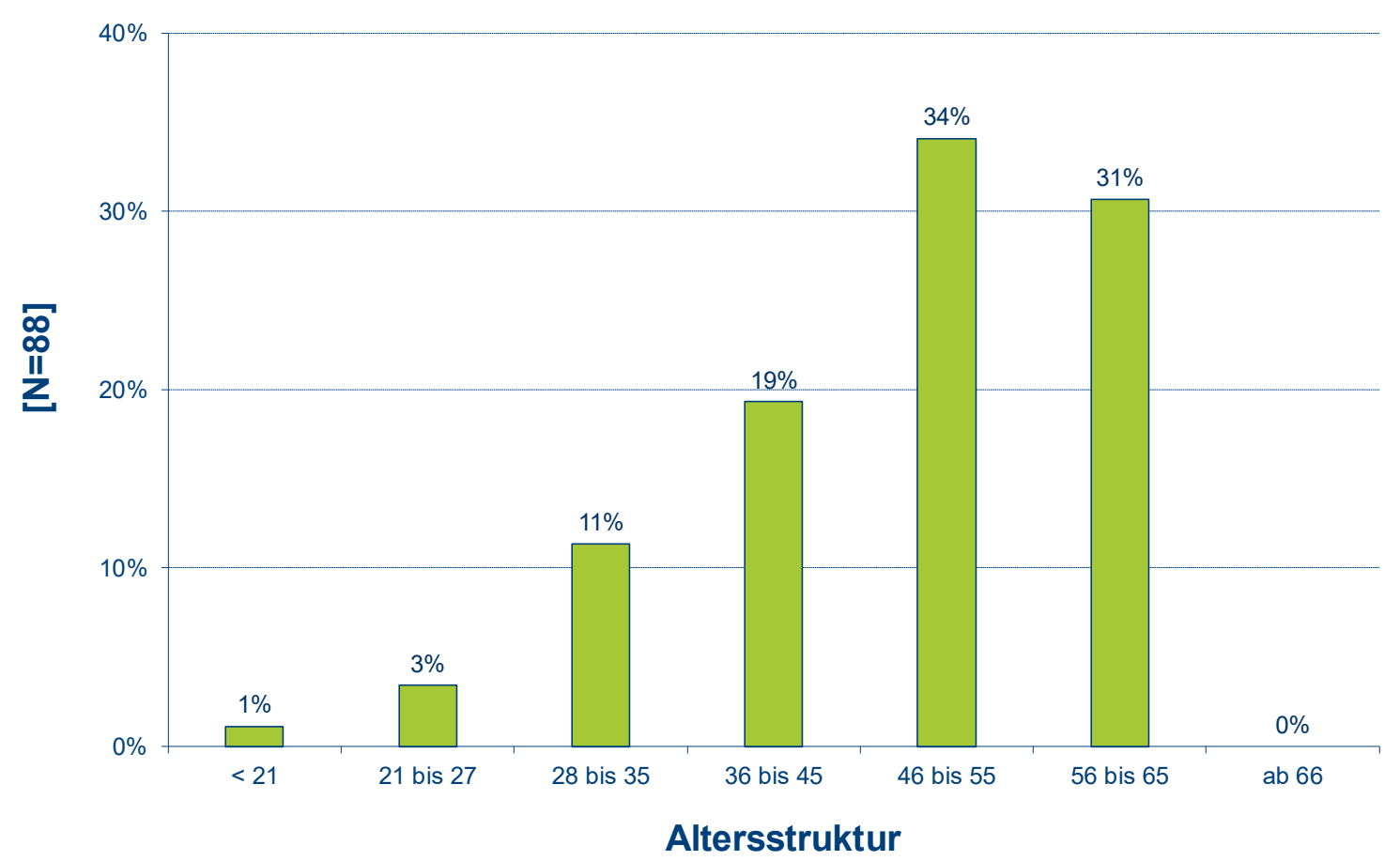




\subsection{Geschlecht}

Diese Frage hatte zum Ziel, herauszufinden, wie viele der befragten Probanden männlich, weiblich oder divers sind.

Das Geschlecht der Befragten verteilt sich mit 66 Prozent auf männliche und mit 34 Prozent auf weibliche Probanden. Keiner der Befragten gibt an, divers zu sein.

\section{Geschlecht}

[N=87]

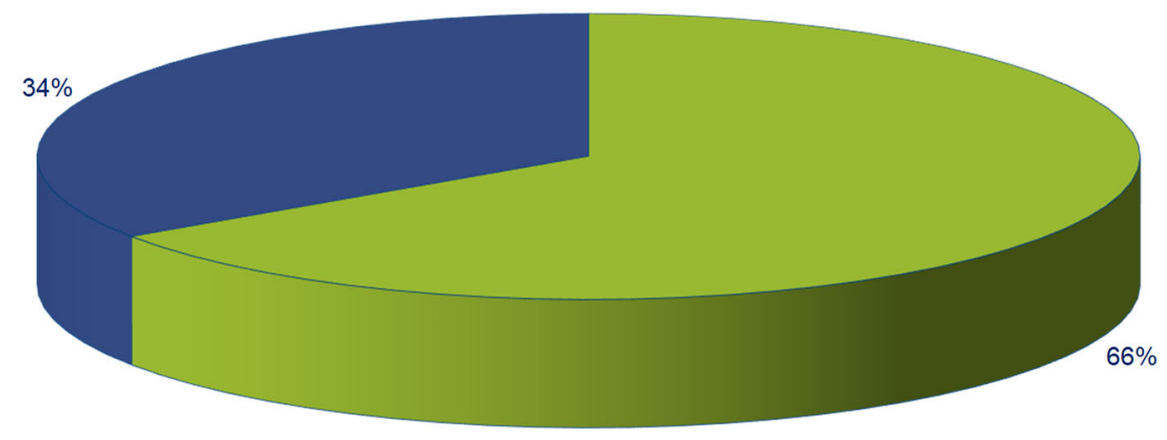

$\square$ Männlich

- Weiblich 


\section{Literatur}

Behringer, S. (2018). Compliance - Prüfstein für die Unternehmensführung, in: Behringer, S. (Hrsg.), Compliance kompakt, 4. Aufl., Berlin.

Bundeskriminalamt (2018). Wirtschaftskriminalität - Bundeslagebild 2018.

Regierungskommission (2019). Deutscher Corporate Governance Kodex, aktuelle Fassung vom 19. Dezember 2019.

Geissler, C. (2004). Compliance Management? Harvard Business Manager, Heft 2/2004.

Schuchter, A. (2012). Perspektiven verurteilter Wirtschaftsstraftäter - Gründe ihrer Handlungen und Prävention in Unternehmen, Wiesbaden. 


\section{Autoren}

Prof. Dr. Patrick Ulrich lehrt Unternehmensführung und -kontrolle als W3-Professor an der Hochschule Aalen und ist Sprecher des Direktoriums des Aalener Instituts für Unternehmensführung (AAUF). Zudem ist er Privatdozent an der Otto-FriedrichUniversität Bamberg.

Prof. Dr. Stefan Behringer hat Betriebswirtschaftslehre an der Universität zu Köln studiert und promovierte zum Themen der Unternehmensbewertung an der Universität Flensburg. Nach dem Doktorat hat er 10 Jahre Managementerfahrung bei der Deutschen Post und der Olympus Europa in den Bereichen Controlling, Mergers \& Acquisitions, Compliance und Interne Revision gesammelt. Seit 2009 ist er Professor für Betriebswirtschaftslehre. Von 2013 bis 2019 war er Präsident der NORDAKADEMIE Hochschule der Wirtschaft in Elmshorn und Hamburg. Seit 2019 ist er am Institut für Finanzdienstleistungen (IFZ) an der Hochschule Luzern als Leiter des Competence Centers Controlling tätig.

Anjuli Unruh ist wissenschaftliche Mitarbeiterin Institut für Finanzdienstleistungen (IFZ) an der Hochschule Luzern seit Anfang 2020. Von 2018 bis Ende 2019 arbeitete sie am Institut für Compliance im Mittelstand an der NORDAKADEMIE. Nach ihren beiden Masterabschlüssen in Wirtschaftswissenschaften (M.Sc.) und Wirtschaftsrecht (LL.M.) entschied sie sich, ihr Wissen im Themenbereich Compliance Management zu vertiefen. Als wissenschaftliche Mitarbeiterin hat sie die Möglichkeit, ihre Fähigkeiten und Fertigkeiten in verschiedenen Compliancerelevanten Forschungsprojekten anzuwenden und zu erweitern. Zudem schreibt sie in diesem Bereich ihre Dissertation.

Vanessa Frank ist wissenschaftliche Mitarbeiterin an der Hochschule Aalen und im Aalener Institut für Unternehmensführung (AAUF) tätig. Nach ihrem Masterabschluss der Betriebswirtschaftslehre (M.Sc.) mit den Schwerpunkten Finanzierung, Unternehmensführung und Controlling an der Otto-Friedrich-Universität Bamberg begann sie an derselbigen Institution ihr Promotionsvorhaben und arbeitet parallel hierzu weiterhin an verschiedenen Forschungsprojekten des Aalener Instituts für Unternehmensführung. 